\title{
TÜRBÜLANSLI YANMA İÇİN DÖNDÜRÜCÜNÜN PARAMETRÍK ÇALIŞMASI
}

\author{
Osman KOCAASLAN*, Tolga YASA** ve Kürşad Melih GÜLEREN*** \\ *Selçuk Üniversitesi Huğlu Meslek Yüksekokulu Makine ve Metal Teknolojileri Bölümü 42700 Beyşehir, Konya, \\ okocaaslan@ selcuk.edu.tr, ORCID: 0000-0002-7848-6974 \\ **Eskişehir Teknik Üniversitesi Mühendislik Fakültesi Makine Mühendisliği Bölümü 26555 Tepebaşı, Eskişehir, \\ tyasa@eskisehir.edu.tr, ORCID: 0000-0002-7242-2507 \\ ***İstanbul Aydın Üniversitesi Uygulamalı Bilimler Yüksekokulu Pilotaj Bölümü 34295 Sefaköy-Küçükçekmece, \\ İstanbul, kmguleren@aydin.edu.tr, ORCID: 0000-0003-3464-7956
}

(Geliş Tarihi: 04.05.2021, Kabul Tarihi: 21.09.2021)

\begin{abstract}
Özet: Bu çalışmada döndürücüye ait kanat sayısı, kanat sarım açısı ve kanat uzunluğu ile yakıt giriş çapının yanma odasındaki türbülanslı akış yapısı, yanma verimi ve emisyon değerleri üzerine etkisi araştırılmıştır. Referans alınan döndürücü kanat sayısı (n), kanat uzunluğu $(\mathrm{L})$, kanat sarım açısı $(\theta)$ ve yakıt giriş çapı $\left(\mathrm{D}_{2}\right)$ sırası ile $10,40 \mathrm{~mm}, 45^{\circ}$, $19.5 \mathrm{~mm}$ 'dir. Kanat sayısı $(6,8,10,12,14)$, kanat uzunluğu $(0.5 \mathrm{~L}, \mathrm{~L}, 1.5 \mathrm{~L}, 2 \mathrm{~L})$, kanat sarım açısı $\left(30^{\circ}, 45^{\circ}, 60^{\circ}, 75^{\circ}, 90^{\circ}\right.$, $\left.120^{\circ}\right)$ ve yakıt giriş çapı için $\left(0.5 \mathrm{D}_{2}, \mathrm{D}_{2}, 1.5 \mathrm{D}_{2}, 2 \mathrm{D}_{2}\right)$ parametrik değerler kullanılarak yeni modeller oluşturulmuştur. Sayısal çalışmalar ANSYS/Fluent 17.2 ticari yazılımı ile gerçekleştirilmiş ve referans alınan deneysel çalışmaya uygun olarak önceden karışmamış yanma modeli tanımlanmıştır. Sayısal yöntem, elde edilen verilerin deneysel veriler ile karşılaştırılması ile doğrulanmıştır. Analizler sonucu olarak kanat sarım açısının alev şekli, kanat uzunluğunun ise alevin simetrik yapısı üzerine önemli etkisinin olduğu bulunmuştur. M04510403900 $\left(\theta=45^{\circ}, \mathrm{n}=10, \mathrm{~L}=40 \mathrm{~mm}\right.$, $\mathrm{D}_{2}=39.00 \mathrm{~mm}$ ) modelinde en yüksek 1 sıl verim elde edilmiş ve $\% 79.3$ olan referans döndürücünün ısıl verimi bu model ile \% 93.8'e yükselmiştir. Yanma odası seyreltme delikleri öncesinde CO kütle fraksiyonu değerinin referans döndürücü modelinde 0.002 olduğu ve M04510400975 $\left(\theta=45^{\circ}, \mathrm{n}=10, \mathrm{~L}=40 \mathrm{~mm}, \mathrm{D}_{2}=9.75 \mathrm{~mm}\right)$ modelinde bu değerin $0.018^{\prime} \mathrm{e}$ yükseldiği tespit edilmiştir.
\end{abstract}

Anahtar Kelimeler: Döndürücü tasarımı, Hesaplamalı Akışkanlar Dinamiği, Kanat sayısı, Kanat uzunluğu, Önceden karışmamış yanma modeli, Sarım açısı, Yakıt giriş çapı.

\section{A PARAMETRIC STUDY ON THE SWIRLER FOR TURBULENT COMBUSTION}

\begin{abstract}
In this study, the effects of the number of swirler blades, swirler blade wrape angle, swirler blade length and the fuel inlet diameter on the turbulent flow structure, combustion efficiency and emission in a combustion chamber have been investigated. The number of blades (n), the blade length (L), the blade wrape angle $(\theta)$ and the fuel inlet diameter $\left(\mathrm{D}_{2}\right)$ of the swirler blades were taken as $10,40 \mathrm{~mm}, 45^{\circ}$ and $19.5 \mathrm{~mm}$, respectively. New models were created using the parameters of the blade number $(6,8,10,12,14)$, the blade length $(0.5 \mathrm{~L}, \mathrm{~L}, 1.5 \mathrm{~L}, 2 \mathrm{~L})$, the blade wrape angle $\left(30^{\circ}, 45^{\circ}, 60^{\circ}, 75^{\circ}, 90^{\circ}, 120^{\circ}\right)$ and the fuel inlet diameter $\left(0.5 \mathrm{D}_{2}, \mathrm{D}_{2}, 1.5 \mathrm{D}_{2}, 2 \mathrm{D}_{2}\right)$. Numerical analysis were performed using ANSYS/Fluent 17.2 commercial software and non-premixed combustion model was defined according to the referenced experimental study. Numerical method was validated with the comparison of numerical and experimental data. It is concluded that the wrape angle has a significant effect on the flame shape and the blade length on the symmetrical structure of the flame. The highest thermal efficiency was obtained for the model M04510403900 $\left(\theta=45^{\circ}\right.$, $\mathrm{n}=10, \mathrm{~L}=40 \mathrm{~mm}, \mathrm{D}_{2}=39.00 \mathrm{~mm}$ ) and the thermal efficiency of the referenced swirler geometry of $79.3 \%$ were increased to $93.8 \%$ with this model. It has been seen that $\mathrm{CO}$ mass fraction value upstream of the dilution holes was 0.002 for referenced swirler model and this value increased to 0.018 for the model M04510400975 $\left(\theta=45^{\circ}, \mathrm{n}=10, \mathrm{~L}=40 \mathrm{~mm}\right.$, $\mathrm{D}_{2}=9.75 \mathrm{~mm}$ ).
\end{abstract}

Keywords: Swirler design, Computational Fluid Dynamics, Blade number, Blade length, Non-premixed combustion, Wrap angle, Fuel inlet diameter.

\section{SEMBOLLER}

$$
\begin{aligned}
& \mathrm{C}_{\mathrm{d}}, \mathrm{C}_{\mathrm{g}} \quad \text { Ampirik katsayılar } \\
& \mathrm{C}_{1}, \mathrm{C}_{2}, \quad \text { Sabit katsay1 } \\
& \mathrm{c}_{\mathrm{p}} \quad \text { Özgül 1sı kapasitesi } \\
& \vec{F} \quad \text { Kuvvet Vektörü [N] } \\
& \text { f Karışım fraksiyonu }
\end{aligned}
$$

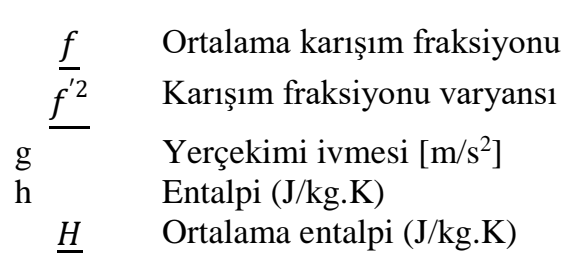




\begin{tabular}{|c|c|}
\hline $\mathrm{k}$ & Türbülans kinetik enerji $\left(\mathrm{m}^{2} / \mathrm{s}^{2}\right)$ \\
\hline $\mathrm{k}_{\mathrm{t}}$ & Türbülans termal iletkenlik [W/m-K] \\
\hline$\dot{m}$ & Kütlesel Debi (kg/s) \\
\hline $\mathrm{n}$ & Döndürücü kanat sayısı \\
\hline $\mathrm{P}$ & Basınç $\left[\mathrm{N} / \mathrm{m}^{2}\right]$ \\
\hline $\mathrm{R}$ & Döndürücü çap1 [m] \\
\hline $\mathrm{S}_{\mathrm{h}}$ & Kaynak terim \\
\hline $\mathrm{S}_{\mathrm{n}}$ & Girdap sayısı \\
\hline $\mathrm{S}_{\mathrm{h}}$ & Kaynak terim \\
\hline $\mathrm{t}$ & Zaman $[\mathrm{s}]$ \\
\hline $\mathrm{U}$ & Eksenel hız $[\mathrm{m} / \mathrm{s}]$ \\
\hline $\mathrm{u}, \vec{v}$ & Hiz vektörü $[\mathrm{m} / \mathrm{s}]$ \\
\hline $\mathrm{V}_{\mathrm{CC}}$ & Yanma odası bölgesi $\left[\mathrm{m}^{3}\right]$ \\
\hline W & Teğetsel hız $[\mathrm{m} / \mathrm{s}]$ \\
\hline $\mathrm{Z}$ & Elemental kütle fraksiyonu \\
\hline$\varepsilon$ & Türbülans kinetik enerji kaybı $\left[\mathrm{m}^{2} / \mathrm{s}^{3}\right]$ \\
\hline$\mu$ & Viskozite $[\mathrm{kg} / \mathrm{m}-\mathrm{s}]$ \\
\hline$\mu_{\mathrm{t}}$ & Türbülanslı viskozite $[\mathrm{kg} / \mathrm{m}-\mathrm{s}]$ \\
\hline$\mu_{1}$ & Laminer viskozite $[\mathrm{kg} / \mathrm{m}-\mathrm{s}]$ \\
\hline$\rho$ & Yoğunluk $\left[\mathrm{kg} / \mathrm{m}^{3}\right]$ \\
\hline$\sigma_{\mathrm{k}}$ & $\mathrm{k}$ için türbülans Prandtl sayısı \\
\hline$\sigma_{\varepsilon}$ & $\varepsilon$ için türbülans Prandtl sayısı \\
\hline$\varphi$ & Eşdeğerlilik oranı \\
\hline
\end{tabular}

\section{GİRIS}

Yanma odaları, gaz türbinli motorlarının oldukça önemli bir bileşendir. $\mathrm{Bu}$ nedenle; yanma odaları tasarımında yanmanın kararlılığı, yüksek yanma verimi ve üretilen emisyon gazlarının konsantrasyon koşulları göz önünde bulundurulmalıdır. Yakıt ve havanın etkili karışımı yanma verimini artırmakta ve yanma sonrası oluşan bazı hidrokarbonların konsantrasyonlarını azaltmaktadır. Yakıt ve havanın etkili karışımı için uygulanan yöntemlerden bir tanesi döndürücü kanat kullanımıdır.

Döndürücü geometrileri üzerine birçok çalışma yürütülmüştür. Bunlardan belli başlı olanlardan, Zhou (2018), beş farklı kanat modeli için yapılan sayısal çalışmalarda LES (Large Eddy Simulation) yöntemi ve RANS (Reynolds-Averaged Navier Stokes) türbülans modellerini kullanmıştır. Sayısal analizlerde döndürücü kanatlarının akış yapısı ve yanma üzerine etkisinin olduğunu belirlemiştir. Yine değişken kanat açılı profiller kullanılarak yapılan deneysel çalışmada girdap yoğunluğunun alev sapma açısını da artırdığı belirlenmiştir (Wang vd., 2015). Patel ve Shah (2019), $30^{\circ}$ kanat açısına sahip döndürücü kullanarak metanın ters difüzyon alevinin yanma karakteristiği üzerine girdap ve döndürücü kanat sayının etkisini incelemiştir. Döndürücünün olduğu deneysel çalışmalarda alev uzunluğunun azaldığı ve en kısa alev uzunluğuna sahip döndürücü profilinin 8 kanatlı olduğu belirlenmiştir. Buna rağmen döndürücülü yanma odasında döndürücü olmayan yanma odasındakine göre daha yüksek sıcaklık değerleri elde edilmiştir. En düşük $\mathrm{NO}_{\mathrm{x}}$ değeri 6 kanatı döndürücüye sahip yanma odasında gözlemlenmiştir. Tret'yakov (2007), üç aşamalı bir döndürücü üzerine yaptıkları geometrik modifikasyonlar ile atomize edilmiş yakıtın döndürücü deflektör duvarları, halkalı stabilizatör ve ayırma kabuğunda biriken yakıt kütlesel fraksiyonlarını incelemişlerdir. Midgley $v d$. (2005), çalışmalarında yakıt enjektörü ile beslenen bir radyal döndürücü ile PIV (Parçacık görüntülemeli hız ölçümü) sistemi kullanarak izotermal deneysel çalışmalar gerçekleştirmiş ve yanma odasındaki akış yapısını incelemişlerdir. PIV sonuçları ile yakıt enjektöründen oluşan ikiz bir girdap dağılımı gözlemlenmiştir. Eldrainy $v d$. (2009), gaz türbinli yanma odalarında yeni bir döndürücü geometrisi üzerine çalışmışlardır. Çalışılan döndürücü geometrinin yenilikçi yanı, aynı giriş kütlesel debisinde girdap sayısı değişkenliğine izin verebilmesidir. Sayısal analizler sonrası değişken teğetsel ve eksenel akış oranı ile girdap sayısının önemli ölçüde değiştiğini gözlemlemişlerdir. Hoda $v d$. (2021), doğalgaz ve alternatif bir yakıt olarak biyogazın gaz türbini yanma odasında simülasyonunu gerçekleştirmişlerdir. Çalışmada iki önemli tasarım parametresi olan girdap sayısı $\left(\mathrm{S}_{\mathrm{g}}\right)$ ve yakıt enjektör çap1 $\left(D_{\text {inj }}\right)$ incelenmiştir. Shahin vd. (2016), basamaklı koniksel bir geometriye sahip döndürücü kullanarak önceden karışmamış (ing. non-premixed) yanma işlemini sayısal ve deneysel olarak incelemişlerdir. Çalışmalarında $5^{\circ}$ eşit açılarda $0^{\circ}-25^{\circ}$ jet açıları için girdap plakaları sonrası hız ve sıcaklık değişimlerini belirlemişlerdir. $10^{\circ}$ ve $15^{\circ}$ 'lik açılardaki girdap plakalarının en düzenli sıcaklık dağılımı ve minimum basınç düşümüne sahip olduğu tespit edilmiştir. Sayyar ve Davani (2021), iç helezonlu bir yanma odasında girdapların önceden karışmamış alev reaksiyonları üzerine etkisini sayısal olarak araştırmıştır. Yanıt Yüzey Metodolojisi (ing. Response Surface Methodology) ile alev kararlılığı, 1sıl verim amaç fonksiyonu ve iki geometrik değişken tanımlaması yapılarak optimize edilmiştir. Sarmalın genişliği ve adımı değiştirildiğinde yanma veriminde iyileştirmelerin meydana geldiği belirlenmiştir.

Yanma verimine etki eden parametrelerden ikisi girdap sayısı ve hava-yakıt oranı değerleridir. Tasarlanan farklı yapılardaki döndürücüler ve kanat yapısındaki geometrik değişiklikler ile döndürücü sonrası girdap sayısında artışlar sağlanabilmektedir. Girdap sayısındaki değişim yanma verimi etkilemekte ve atık gaz derişimini azaltabilmektedir. Bu kapsamda Prakash vd. (2020)'in yaptığı çalışmada, önceden karışmamış ve girdap kararlılığı sağlanmış bir gaz türbin yanma odasında girdaplı yakıt enjeksiyonunun alev kararlılığı ve emisyon karakteristiğine etkisi deneysel olarak incelenmiştir. Çalışmada üç farklı yakıt enjeksiyon konfigürasyonu kullanılmıştır. Yanma odasına hava yanma odasına saat yönünün tersi doğrultusunda yakıt ise a) girdapsız yakıt girişi b) saat yönünde ve c) saat yönüne ters doğrultuda girdaplı yakıt girişi sağlanmıştır. Deneysel çalışmalarda global eşdeğerlilik oranı $0.2-1$ aralığında tercih edilmiştir. Sonuç olarak tüm çalışma koşullarında yanma odasında çok düşük seviyelerde $\mathrm{NO}_{\mathrm{x}}$ varlığı tespit edilmiştir. Global eşdeğerlilik oranı artışı $\mathrm{NO}_{\mathrm{x}}$ oluşumunu da artırmıştır. Yakıt enjeksiyon konfigürasyonları karşılaştırıldığında " $b$ " koşulunda diğer konfigürasyonlara göre daha düşün NOx emisyonu elde edilmiştir. Alev uzunluğunun (ing. flame standoff distance) "c" koşulunda diğer konfigürasyonlara göre 
daha düşük değerlere indirgendiği belirlenmiştir. Yakıt ve havanın "c" konfigürasyonunda diğer konfigürasyonlara göre daha hızlı karıştığı ve daha yüksek reaktivitenin meydana geldiği görülmüştür. İlbaş $v d$. (2016), gaz yakıcı bir yanma odasında girdap sayısının hidrojen içeren yakıtların yanma karakteristiği üzerine etkisini incelemiştir. Girdap sayısının alev sıcaklığına etkisinin büyük olduğu gözlemlenmiştir ve girdap sayısındaki değişkenliğin yüksek $\mathrm{NO}_{x}$ bölgelerinin meydana gelmesine neden olduğu da tespit edilmiştir. Pourhoseini ve Asadi (2017)'nin deneysel çalışmasında $0^{\circ}, 40^{\circ}$ ve $80^{\circ}$ kanat açılı döndürücüler kullanılmıştır. Deneysel sonuçlar döndürücü kanat açılarının yanma verimi, sıcaklık, CO ve NO atık gazları derişimleri üzerine oldukça büyük etkisinin olduğunu göstermiştir. Optimum kanat açısı ile yakıt ve hava karışımının en yüksek seviyelere ulaştırılabileceği, CO ve NO vb. atık gaz derişimlerinin azaltılabileceği belirtilmiştir. Shah (2015), farklı kanat açılarına sahip döndürücü profilleri ve farklı AFR (hava-yakıt oranı) koşullarında boru tipi yanma odası çıkışındaki sıcaklık ve emisyon değerlerindeki değişimleri deneysel olarak incelemiştir. Sıcaklık değerleri incelendiğinde döndürücü sonrası birincil bölgedeki girdap ve birincil jet varlığı nedeniyle maksimum sicaklığın yanma odası çıkışında cidar bölgesinde oluştuğu belirlenmiştir. Artan döndürücü kanat açısı ile yanma odası çıkışındaki sıcaklık gradyanlarında düşüşlerin meydana geldiği gözlemlenmiştir. Aynı kanat açısında yüksek AFR değerlerinde yanma odası çıkışında sıcaklık değerleri azalmıştır. AFR değeri arttıkça CO emisyon değerinin de azaldığı belirlenmiştir. Ayrıca yine kanat açısındaki artış CO emisyon değerinin azalmasını sağlamıştır. Rajabi ve Amani (2018), deneysel yanma verileri (Sandia Flame D ve BERL yanma odası) kullanarak ve halkalı tip bir yanma odasında sayısal çalışmalar yürüterek entropi üretim karakteristiği üzerine girdap sayısının etkisini incelemiştir. Sonuç olarak düşük girdap sayılarında reaksiyonun, yüksek girdap sayılarında 1sı transferinin katkısı ile 1sı transferi ve reaksiyonun entropi üretiminde baskın bir rol oynadığı belirlenmiştir.

Literatürde döndürücü kanat yapıları üzerine yapılan çalışmalarda kanat sarım açısı ve kanat sayısının değişimi üzerinde durulmuştur. Kanatlı yapılarda kanat sayısı ve kanat sarım açısının yanında akış yapısını etkileyen tasarım parametrelerinden bir tanesinin de kanat uzunluğu olabileceği gerçeği göz ardı edilmiştir. Artan ya da azalan kanat uzunluğunun, kanat çıkışında akış yapısını önemli ölçüde değiştireceği düşünülmektedir. Bu durum yanma odalarında yakıt ve hava karışımının homojenliğini ve yanmanın dinamik yapısını da etkileyebilir. Yakıt ve hava karışımının homojen yapısına etki eden bir başka unsurun da yakıt giriş hızı olabileceği bu çalışmada değerlendirilmiştir. $\mathrm{Bu}$ yeni değişkenlerle birlikte bu çalışmada, döndürücü kanatları sarım açısı, kanat sayısı, kanat uzunluğu ve yakıt giriş çapının yanma verimi ve emisyon değerlerinin üzerine etkisi incelenmiştir. Ayrıca türbülanslı akış yapısı ayrıntılı çalışılmıştır. İlk aşamada referans alınan yanma odası için sayısal analizler uygulanmıştır. Referans alınan deneysel çalışmadaki döndürücünün kanat sayısı 10 , kanat sarım açısı ise $45^{\circ}$ 'dir. Yanma odası $2 \mathrm{~m}$ uzunluğunda olup 6 adet seyreltme deliği yer almaktadır. Deneysel ve sayısal veriler karşılaştırılmıştır. Çalışmanın ikinci aşamasında kanat sayısı, kanat uzunluğu, kanat sarım açısı ve yakıt giriş çapı değiştirilerek elde edilen geometriler için sayısal analizler yapılmıştır. Çalışmanın son aşamasında referans alınan eşdeğerlilik oranında $(\varphi=0.679)$ en yüksek yanma verimine sahip döndürücü profili için stokiyometrik ve zengin yanma şartlarında döndürücü modelinin etkisi gözlemlenmiştir. Sayısal analiz sonuçlarına göre farklı döndürücüler ile akış yapısı, yanma verimi ve emisyon değerlerindeki değişim incelenmiştir.

\section{MATERYAL ve YÖNTEM}

\section{Döndürücü Geometrileri}

Yanma odalarında birincil bölgede yakıt ve havanın daha etkili karışabilmesi ve bu sayede yüksek verimli yanma elde edebilmek için döndürücüler kullanılmaktadır. Döndürücüler, girdap sayısını artırılabilmektedir. Bu artış, yanma reaksiyonlarını pozitif yönde etkilemekte ve $\mathrm{NO}_{\mathrm{x}}$ konsantrasyonunu azaltmaktadır (Shah vd. 2015, Jeong $v d$. 2004). Bu çalışmada referans alınan bir yanma odasındaki döndürücü yeniden ele alınmış ve oluşturulan yeni geometriler için sayısal analizler yürütülmüştür. Referans alınan döndürücü, eksenel tipte olup $45^{\circ}$ sarım açısı ve 10 adet kanada sahiptir. Yakıt döndürücü merkezindeki $19.5 \mathrm{~mm}$ çapındaki açıklıktan girerken; hava döndürücülerin bulunduğu iç çapı $42.5 \mathrm{~mm}$, dış çapı ise $78.1 \mathrm{~mm}$ olan açıklıktan yanma odasına girmektedir. Referans geometriye ait tasarım parametreleri Şekil 1'de paylaşılmıştır (Serag-Eldin ve Spaldin, 1979).

Döndürücü kanatlar, hava hız vektörlerini ve buna bağl1 olarak girdap yapısını değiştirdiğinden yanma kinematiği üzerine önemli etkilere sahiptir. Yanma kinematiği ile döndürücü tasarımı arasındaki ilişkinin anlaşılabilmesi için kanat sayısı, kanat uzunluğu, kanat sarım açısı ve yakıt giriş çapı değiştirilerek 16 farklı döndürücü geometrisi oluşturulmuştur.

İlk yapılan sayısal analizlerde kanat sayısı $6,8,10$, 12 ve 14 olacak şekilde değiştirilmiş, kanat sarım açısı $\left(\theta=45^{\circ}\right)$, yakıt giriş çap1 $\left(\mathrm{D}_{2}=19.5 \mathrm{~mm}\right)$, döndürücü giriş çap1 $\left(\mathrm{D}_{1}=78.1 \mathrm{~mm}\right)$ ve kanat kalınlığ 1 değiştirilmemiştir. Kanat sayısına ek olarak kanat uzunluğunun etkisi de referans geometrinin kanat uzunluğu olan $\mathrm{L}=40 \mathrm{~mm}$ değiştirilerek $0.5 \mathrm{~L}, \mathrm{~L}, 1.5 \mathrm{~L}$ ve $2 \mathrm{~L}$ şeklinde oluşturulan döndürücüler ile incelenmiştir. Kanat uzunluğu çalışmalarında kanat sarım açısı, döndürücü giriş çapı, yakıt giriş çap1 ve kanat kalınlığ sabit tutulmuştur. Ayrıca kanat sarım açısı da döndürücü çıkışındaki hız vektörleri üzerinde etkilidir. $\mathrm{Bu}$ amaçla farklı sarım açılarına $\left(30^{\circ}, 45^{\circ}, 60^{\circ}, 75^{\circ}, 90^{\circ}\right.$ ve $\left.120^{\circ}\right)$ sahip geometrilerin akış alanına olan etkileri incelenmiştir. 


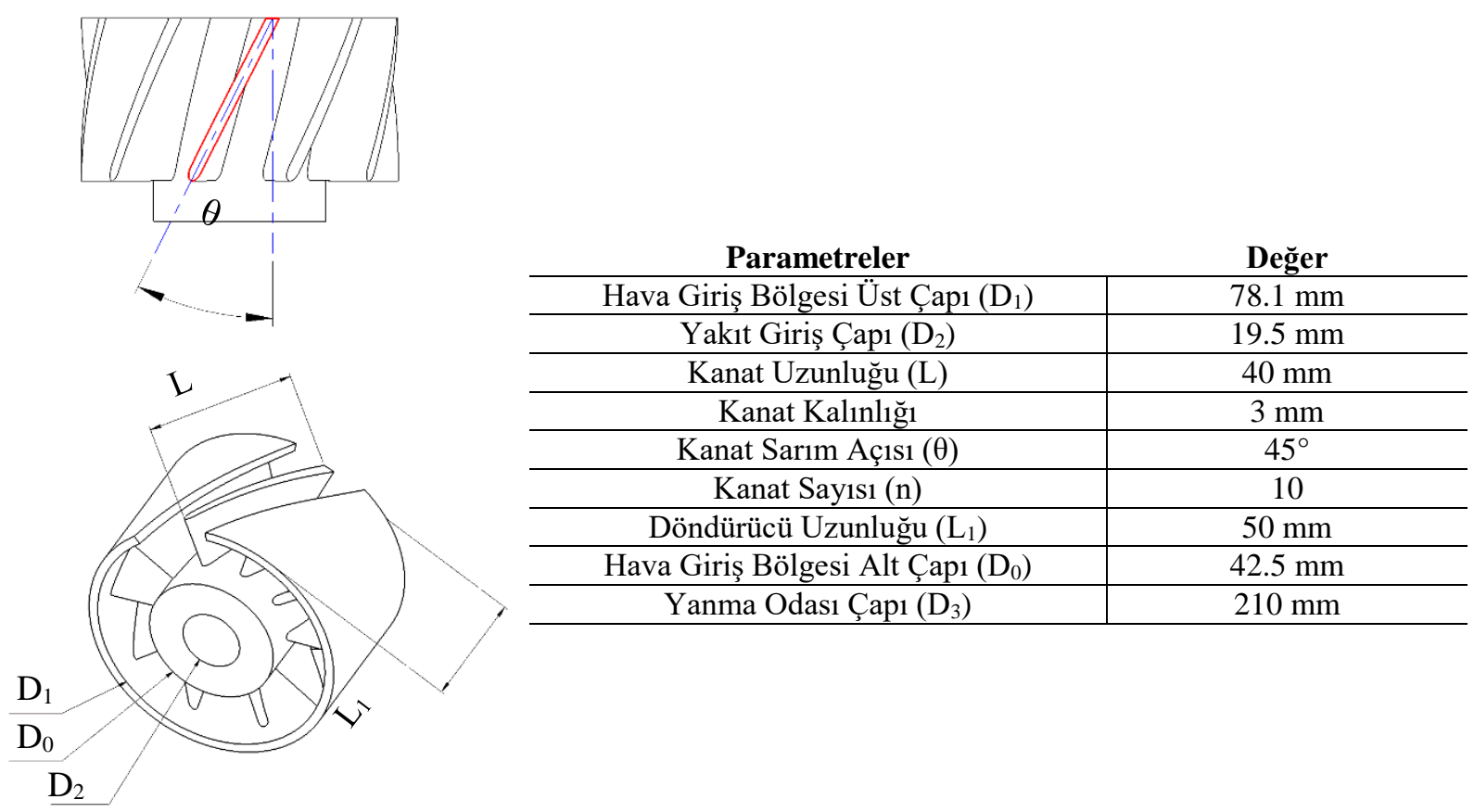

Şekil 1. Döndürücü tasarım parametreleri (Serag-Eldin ve Spaldin, 1979).

Tablo 1. Tasarlanan döndürücü geometrileri ayrıntıları.

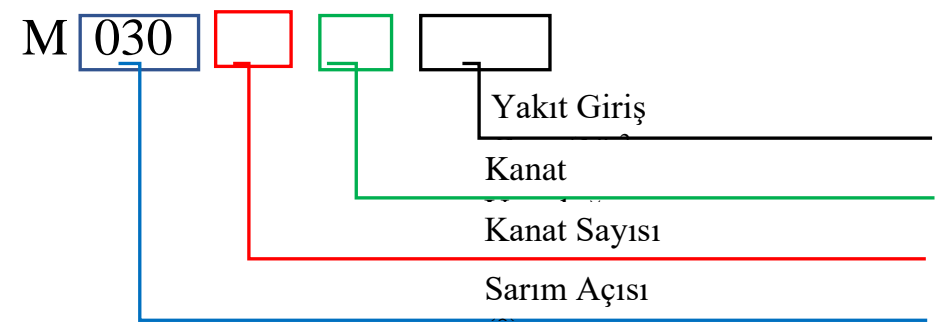

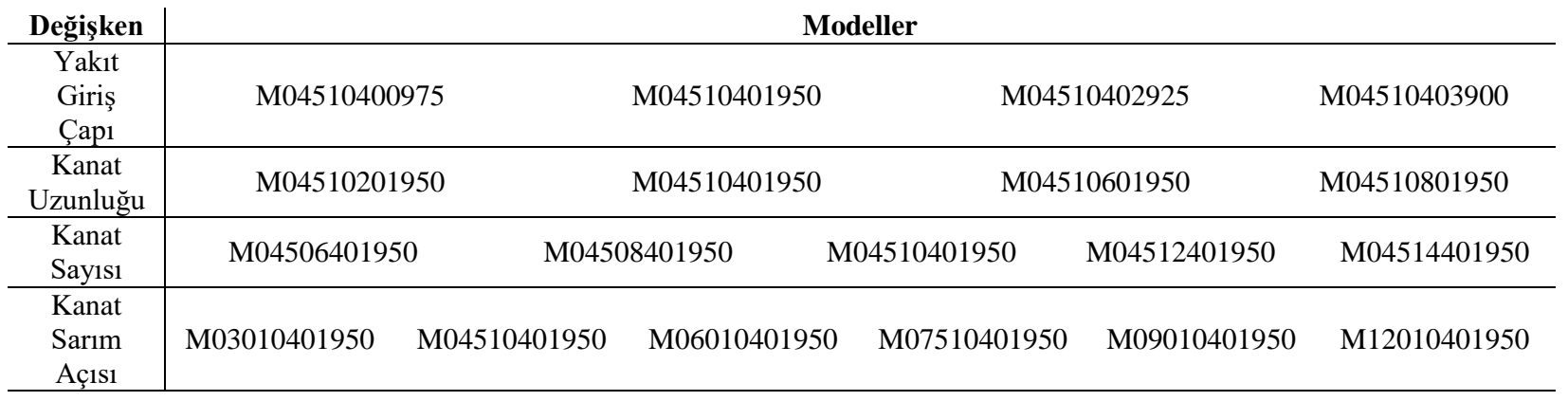

Kanat sarım açısı çalışmasında kanat uzunluğu, döndürücü giriş çap1, yakıt giriş çap1 ve kanat kalınlığı değiştirilmemiş olup referans modele ait değerler kullanılmıştır. Son olarak yakıt giriş çapının yanma verimi üzerine etkisini incelemek için $0.5 \mathrm{D}_{2}, \mathrm{D}_{2}, 1.5 \mathrm{D}_{2}$ ve $2 \mathrm{D}_{2}$ çapında modeller oluşturulmuştur. Yakıt giriş çapı çalışmasında kanat uzunluğu, döndürücü giriş çapı, kanat kalınlığı ve kanat sarım açısı değerlerinde aynı bırakılmıştır. Oluşturulan 16 geometri Şekil 2'de verilmiştir ve Tablo 1 'de özetlenmiştir. Analizlerde kullanılacak olan referans yanma odası (Şekil 2) 2000 $\mathrm{mm}$ uzunluğa ve $210 \mathrm{~mm}$ çapa $\left(\mathrm{D}_{3}\right)$ sahiptir. Yanma odası üzerinde girişten $240 \mathrm{~mm}$ uzaklıkta çevresel olarak dağıtılmış $25.4 \mathrm{~mm}$ çapında 6 adet seyreltme deliği bulunmaktadır. Yanma odasına hava ve yakıt, eksenel bir döndürücü ile giriş yaparak karışmaktadır (Serag-Eldin ve Spaldin, 1979). 


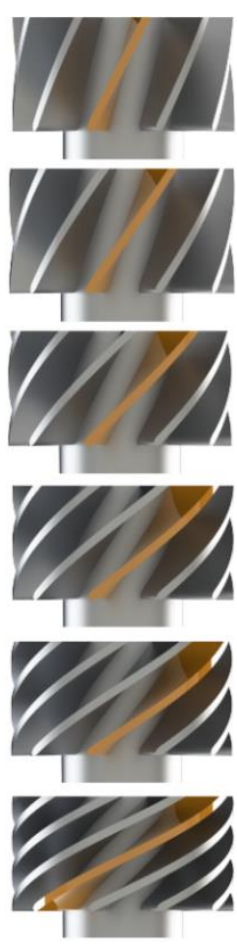

a)

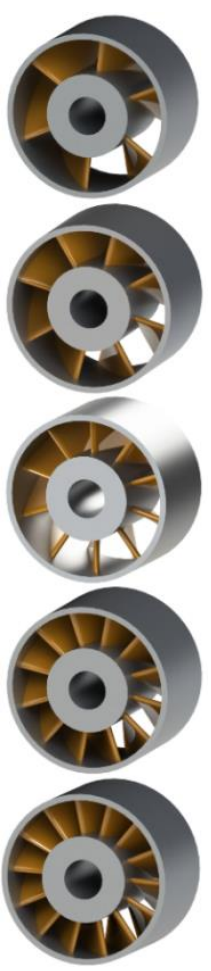

b)

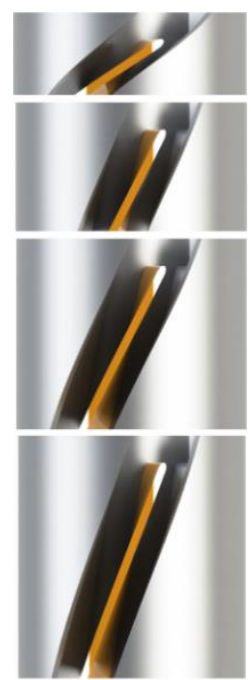

c)

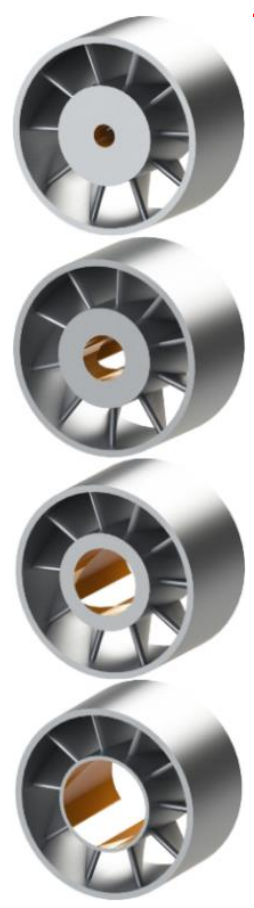

d)

Sekil 2. Tasarlanan döndürücü geometrilerin gösterimi a) $30^{\circ}-120^{\circ}$ kanat sarım açısı b) 6-14 kanat c) $0.5 \mathrm{~L}-2 \mathrm{~L}$ kanat uzunluğu d) $0.5 \mathrm{D}_{2}-2 \mathrm{D}_{2}$ yakıt giriş çap1

\section{Sayısal Yöntem}

Sayısal çalışmalarda çözüm ağında yer alan hücrelerin dağılımı, sayısal sonuçları etkilemekte ve akış fiziğine uygun sonuçlar elde edilip edilemeyeceğini belirlemektedir. Bu nedenle sayısal çalışmalar öncesi tasarlanan geometrilere uygun akış hacimleri oluşturulmuş ve referans alınan döndürücü ile uyumlu çözüm ağ1 yapısı tespit edilmiştir. Araştırmada kullanılacak çözüm ağının oluşturulacağı akış hacimleri ve sınır koşullarının tanımlanacağı yüzeyler
Şekil 3'te verilmiştir. Uygun çözüm ağının saptanabilmesi için Tablo 2'de verilen özelliklerde 5 farklı çözüm ağı oluşturulmuştur.

Tablo 2. Sayısal analizlerde kullanılan çözüm ağları.

\begin{tabular}{l|l|l} 
Çözüm Ağı & Hücre Yapısı & Hücre Sayısı \\
\hline 1 & Düzgün Dörtyüzlü & $0.568 \times 10^{6}$ \\
2 & Düzgün Dörtyüzlü & $0.642 \times 10^{6}$ \\
3 & Dörtyüzlü & $1.710 \times 10^{6}$ \\
4 & Dörtyüzlü & $3.450 \times 10^{6}$ \\
5 & Dörtyüzlü & $6.700 \times 10^{6}$
\end{tabular}

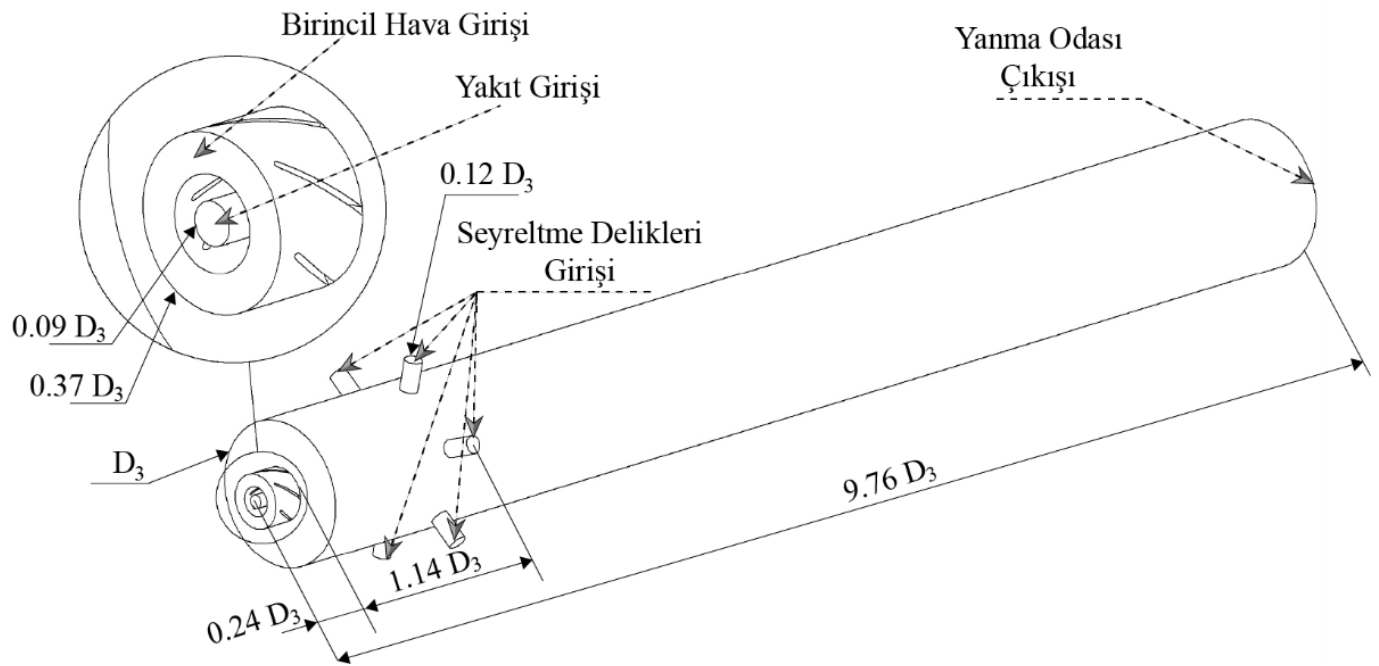

Şekil 3. Boru halkalı tipi yanma odası için oluşturulan akış hacmi. 
Yanma odası içerisinde hava-yakıt karışımının hızlı bir şekilde karışabilmesinde türbülanslı akış özelliklerinden faydalanılmaktadır. Bu sebeple yanma odası içerisindeki akışın türbülans karakteristiklerinin modellenmesinde Abubakar vd. (2018), tarafından da önerilen k- $\varepsilon$ türbülans modeli kullanılmıştır ve sayısal çalışmalar ticari yazılım olan ANSYS/Fluent 17.2 ile gerçekleştirilmiştir. Öte yandan hava ve yakıtın ayrı ayrı yanma odasına girip burada karışmasından dolayı önceden karışmamış yanma modeli tercih edilmiştir. Yanma ve türbülans modellerinin yanında sıkıştırılabilir akış ve 1sı transferi nedeniyle sayısal analizlere enerji denklemleri de dahil edilmiştir. Aşağıda sayısal çözümlemelerde kullanılan süreklilik, momentum ve enerji denklemleri verilmiştir (Abubakar vd, 2018).

$$
\begin{gathered}
\frac{\partial \rho}{\partial t}+\frac{\partial\left(\rho u_{i}\right)}{\partial x_{i}}=0 \\
\frac{\partial}{\partial t}(\rho \vec{v})+\vec{\nabla}(\rho \vec{v} \vec{v})=-\nabla P+\mu \nabla^{2} \vec{V}+\rho \vec{g}+\vec{F} \\
\frac{\partial}{\partial t}(\rho E)+\nabla \cdot(\vec{v}(\rho E+p)) \\
=-\nabla \cdot\left(\sum_{j} h_{j} J_{j}\right)+ \\
S_{h}
\end{gathered}
$$

Türbülanslı akış probleminin çözülmesi için kullanılan standart k- $\varepsilon$ türbülans modelinde türbülans kinetik enerji (k) ve türbülans kinetik enerji yitim oranının ( $\varepsilon$ ) hesaplanması gerekmektedir. Denklem (4) ve (5)'te k ve $\varepsilon$ değerinin hesaplanabilmesi için kullanılan transport denklemler verilmiştir. Denklem 4 ve 5 'te verilen $\mathrm{C}_{1}, \mathrm{C}_{2}$, $\sigma_{\mathrm{k}}$ ve $\sigma_{\varepsilon}$ parametreleri sabit katsayılardır ve değerleri sırası ile 1.44, 1.92, 1 ve 1.3 olarak seçilmiştir (Launder ve Spalding, 1974).

$$
\begin{gathered}
\frac{D k}{D t}=\frac{1}{\rho} \frac{\partial}{\partial x_{k}}\left[\frac{\mu_{t}}{\sigma_{k}} \frac{\partial k}{\partial x_{k}}\right]+\frac{\mu_{t}}{\rho}\left(\frac{\partial U_{i}}{\partial x_{k}}+\frac{\partial U_{k}}{\partial x_{i}}\right) \frac{\partial U_{i}}{\partial x_{k}} \\
\frac{D \varepsilon}{D t}=\frac{1}{\rho} \frac{\partial}{\partial x_{k}}\left[\frac{\mu_{t}}{\sigma_{\varepsilon}} \frac{\partial \varepsilon}{\partial x_{k}}\right]+ \\
\frac{C_{1} \mu_{t}}{\rho} \frac{\varepsilon}{k}\left(\frac{\partial U_{i}}{\partial x_{k}}+\frac{\partial U_{k}}{\partial x_{i}}\right) \frac{\partial U_{i}}{\partial x_{k}}-C_{2} \frac{\varepsilon^{2}}{k} \\
\mu_{t}=\frac{C_{\mu} \rho k^{2}}{\varepsilon}
\end{gathered}
$$

Türbülanslı önceden karışmamış yanma probleminin modellenebilmesi için iki farklı yaklaşım mevcuttur. Bunlar basit değişken yöntemi (ing. Primitive variable method) ve reaksiyon hızı yaklaşımıdır (ing. Reaction rate approach). Basit değişken yönteminde türlerin kütle fraksiyonları, sıcaklık dengesi denklemleri (balance equation) ve reaksiyon hızının modellenmesine ihtiyaç duyulmamaktadır. RANS kodları olasılık yoğunluk fonksiyonunu (PDF) tahmin edebilmek için akış değişkenleri ve karışım fraksiyon değişkenlerini çözmektedir (Poinsot ve Veynante, 2005). Sayısal çalışmalarda önceden karışmamış yanma problemi için PDF/Mixture Fraction modeli kullanılmıştır. Bu model, deneysel sonuçlara yakın değerlerin elde edilebilmesi için tercih edilmektedir (İlbaş $v d$, 2016). Yakıt ve havanın birleşmesi ile çoklu kimyasal etkileşim oluşmaktadır. Hızlı gerçekleşen reaksiyonlar ve türbülanslı alevler ile ilgili çözümlemelerde akış fiziğinin karmaşıklığından dolayı sadeleştirmeler yapılmaktadır. Hesaplamalarda, tüm türlerin eşit difüzyon katsayılarına sahip olduğu varsayımı uygulanmaktadır. Bu varsayım, gazın termokimyasal durumunu korumakta olup hesaplamalarda karışım oranının belirlenmesini gerektirmektedir (Jones ve Whitelaw, 1982). Karışım oranının genel formu Denklem 7'de verilmiştir. Burada $\mathrm{Z}_{\mathrm{i}}$ elemental kütle fraksiyonunu, " $\mathrm{i}$ " ise elementi tanımlamaktadır. Karışım fraksiyonu (f) sayısal analizlerde oksitleyici için "0", yakıt için " 1 " değeri tanımlanmaktadır. Karışım kesrinin ortalama ve değişken değerleri ile türbülanslı kimya etkileşimini incelemek için Denklem 8'de verilen transport denklemi sayısal olarak çözülmelidir. Denklem 8 'de verilen $C_{d}$ ve $\mathrm{C}_{\mathrm{g}}$ ampirik katsayılar olup değerleri sırası ile 2.0 ve 2.8'dir (Abubakar vd, 2018).

$$
\begin{gathered}
F=\frac{Z_{i}-Z_{I, o x}}{Z_{I, f u e l}-Z_{I, o x}} \\
\nabla \cdot\left(\rho \underline{\vec{u} f^{\prime 2}}\right)=\nabla \cdot\left(\frac{\mu_{l}+\mu_{t}}{\sigma_{t}} \nabla f^{\prime 2}\right)+ \\
C_{g} \mu_{t}(\nabla \underline{f})^{2} C_{d} \frac{\rho \varepsilon}{k} f^{\prime 2}
\end{gathered}
$$

Adyabatik olmayan yanma uygulamalarında 1s1 transferi sıcaklık ve tür kütle fraksiyonunu etkilemektedir. Bu etkinin de sayısal çözümlemelere ilave edilmesi için Denklem 9'da verilen ortalama entalpi transport denklemi kullanılmaktadır. Her bir termokimyasal skaler (sıcaklık, tür kütle fraksiyonu vb.) kimyasal denge varsayımı ile karışım fraksiyonu ve ortalama entalpinin bir fonksiyonu olarak hesaplanmaktadır. Sonuç olarak bu skalerlerin anlık değerleri ile ortalama değerlerini ilişkilendiren bir modele ihtiyaç duyulmaktadır. Önceden karışmamış yanma modellemesinde varsayılan-şekil olasılık yoğunluk fonksiyonu (ing. Assumed-shape probability density function) kullanılmaktadır. Sayısal çalışmalarda $\beta$-fonksiyon varsayımı PDF kullanılmıştır. Transport denklemlerin çözümü öncesinde termokimyasal skalerleri içeren bir tablo oluşturulmaktadır. Hesaplanan bu PDF tablolar, çözüm sirasinda tablo enterpolasyonu ile look-up tablosu olarak kullanılır. B-fonksiyon varsayımı PDF Denklem 10'da verilmiştir (Abubakar vd, 2018).

$$
\begin{array}{r}
\nabla(\rho \vec{u} \underline{H})=\nabla\left(\frac{k_{t}}{c_{p}} \nabla \underline{H}\right)+S_{h} \\
p(f)=\frac{f^{\alpha-1}(1-f)^{\beta-1}}{\int \quad f^{\alpha-1}(1-f)^{\beta-1} d f} \\
\alpha=\underline{f}\left[\frac{f(1-\underline{f})}{\left.\underline{f^{\prime 2}}-1\right]}\right.
\end{array}
$$




$$
\beta=(1-\underline{f})\left[\frac{\underline{f(1-\underline{f})}}{\underline{f^{\prime 2}}}-1\right]
$$

Sayısal analizlerde referans alınan çalışmada belirtilen sınır şartları kullanılmıştır. Sınır şartları tanımlanabilmesi için yakıt ve hava girişi, seyreltme

Tablo 3. Sınır koşulları (Serag-Eldin ve Spaldin, 1979).

\begin{tabular}{l|l|ll} 
Yüzeyler & Sinır Koşulu & Değer & \\
\hline Yakıt Giriși & Kütlesel Debi, Sıcaklık & $\varphi=0.697-1-1.2$ & $\mathrm{~T}_{\mathrm{f}}=500 \mathrm{~K}$ \\
\hline Hava Giriși & Kütlesel Debi, Sicaklık & $\varphi=0.697-1-1.2$ & $\mathrm{~T}_{\mathrm{a}}=500 \mathrm{~K}$ \\
\hline Seyreltme Delikleri Girişi & Kütlesel Debi, Sicaklık & $\dot{m}_{s}=0.039 \mathrm{~kg} / \mathrm{s}$ & $\mathrm{T}_{\mathrm{s}}=310 \mathrm{~K}$ \\
\hline Çıkış Basınc1 & Basınç & $\mathrm{P}_{\mathrm{o}}=600 \mathrm{kPa}$ & \\
\hline Yanma Odası Duvarları & Sicaklık & $\mathrm{T}_{\mathrm{cc}}=300 \mathrm{~K}$ &
\end{tabular}

delikleri girişi, yanma odası çıkışı ve yanma odası duvar yüzeyleri oluşturulmuştur. Referans çalışmada yakıt, hava ve seyreltme deliklerine kütlesel debi ve sıcaklık; yanma odası çıkışına basınç, yanma odası duvarlarına ise sıcaklık ve kaymama şartı tanımlanmıştır. Sınır şartları ve tanımlanan değerler Tablo 3'de verilmiştir.

Yanmanın kinematiği incelendiğinde yanma sonrası küçük zaman aralıklarında birçok tür oluşmakta ve bu türler farklı bileşenlere tekrar dönüşmektedir. Oluşan bu ürünlerin belirlenmesi ve akış problemine tanımlanması yanmanın çözülmesi konusunda büyük bir önem taşımaktadır. Bu nedenle sayısal çözümlerde yakıt, hava ve yanma sonrası oluşan ürünler tanımlanmıştır. Yanma sonrası yirmi ürün belirlenmiş ve Tablo 4'te gösterilmiştir. Sayısal çalışmalarda sürdürülen yanma olayı eşdeğerlilik oranı $(\varphi) 0.697$ olan fakir bir karışım ile gerçekleştirilmiştir (Serag-Eldin ve Spaldin, 1979). Yakıt kompozisyonu Tablo 5'de verilmiştir. Sayısal çalışmalarda zamana dayalı analizler yapılmış, bu çapının giriş hava hızına oranının \% 1 'ine denk gelen 0.002026 saniyelik zaman adımları kullanılarak ilk 5000 zaman adımı için (10.13 saniye) çözümler elde edilmiştir. Analizler Eskişehir Teknik Üniversitesi'nde bulunan Intel ${ }^{\circledR}$ Xeon ${ }^{\circledR}$ E5-2630 modeli 2.3 Ghz hizında 24 işlemcili iş istasyonunda koşturulmuştur. Her bir analiz yaklaşık 1 hafta sürmüştür.

Tablo 4. Yakıt, hava ve yanma sonrası oluşan ürünler.

\begin{tabular}{c|c|c} 
Yakıt & Oksitleyici & Ürünler \\
\hline $\mathrm{N}_{2}$ & $\mathrm{O}_{2}$ & $\mathrm{CO}$ \\
$\mathrm{CH}_{4}$ & $\mathrm{~N}_{2}$ & $\mathrm{CO}_{2}$ \\
$\mathrm{C}_{3} \mathrm{H}_{8}$ & & $\mathrm{C}<\mathrm{s}>$, \\
$\mathrm{C}_{2} \mathrm{H}_{6}$ & & $\mathrm{H}_{2}$ \\
& & $\mathrm{H}_{2} \mathrm{O}$ \\
& & $\mathrm{OH}$ \\
& & $\mathrm{H}$ \\
& & $\mathrm{HO}_{2}$ \\
& & $\mathrm{H}_{2} \mathrm{O}_{2}$ \\
& & $\mathrm{HCO}$ \\
& & $\mathrm{CHO}$ \\
& & $\mathrm{HOCO}$
\end{tabular}

\section{$\mathrm{HCOOH}$}

Döndürücüler yanma odalarında yakıt ve hava karışımını artırıcı roller üstlenmektedir. Yakıt ve hava karışımını girdap sayısı ile ilişkilendirmek mümkündür. Döndürücüler ile girdap sayısındaki yükseliş aynı zamanda yanma odasında yakıt ve hava karışımını da artırmaktadır (Yılmaz, 2013). Girdap sayısı (Denklem 13), açısal momentum akısının eksenel momentum akısına oranı olarak tanımlanır ve boyutsuz bir parametredir (Kwark $v d, 2004)$. W ve $\mathrm{U}$ teğetsel ve eksenel hız bileşenleri olup $\mathrm{R}$ değeri ise döndürücü çapıdır (Eldrainy vd, 2009).

$$
S_{n}=\frac{\int_{0}^{R} \rho U W r^{2} d r}{R \int_{0}^{R} \rho U^{2} r d r}
$$

Tablo 5. Yakıt kompozisyonu (Serag-Eldin ve Spaldin, 1979).

\begin{tabular}{l|l} 
Bileşenler & Kompozisyon (\%) \\
\hline $\mathrm{CH}_{4}$ & 93.63 \\
$\mathrm{C}_{2} \mathrm{H}_{6}$ & 3.25 \\
$\mathrm{C}_{3} \mathrm{H}_{8}$ & 0.69 \\
$\mathrm{~N}_{2}$ & 1.78
\end{tabular}

\section{BULGULAR}

\section{Sayısal ve Deneysel Çalışmaların Karşılaştırılması}

Yanma odası girişinden eksenel doğrultuda 320 ve 360 mm uzaklıkta yer alan düzlemlerdeki akışkan sıcaklığının radyal yöndeki değişimi, Tablo 2'de verilen farklı çözüm ağları ile yapılan sayısal analizler ve referans deneysel çalışma için karşılaştırılmış ve Şekil 4 'te sunulmuştur. Sonuçlar incelendiğinde deneysel verilere en yakın sonuçların 3 numaralı çözüm ağı ile elde edildiği görülmektedir. Bu sebeple bu çalışmadaki analizlerde 3 numara ile gösterilen dörtyüzlü ve yapısız özellikte olan 1.71 milyon hücreye sahip çözüm ağ1 kullanılmıştır. 


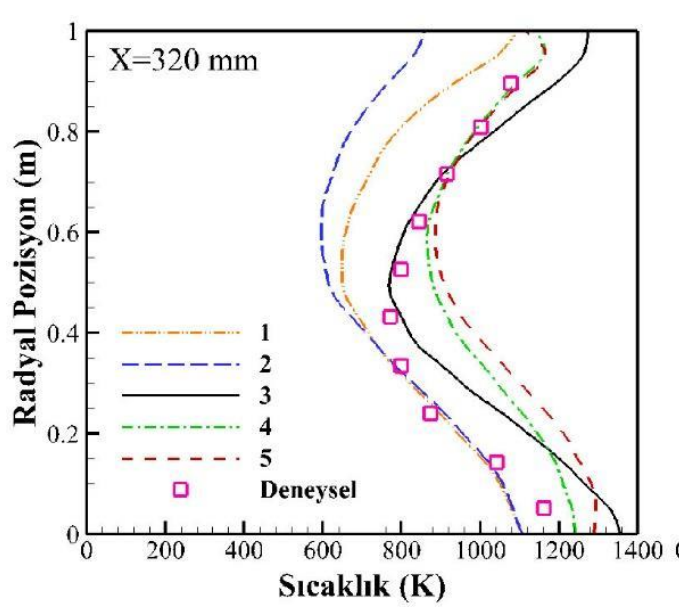

a)

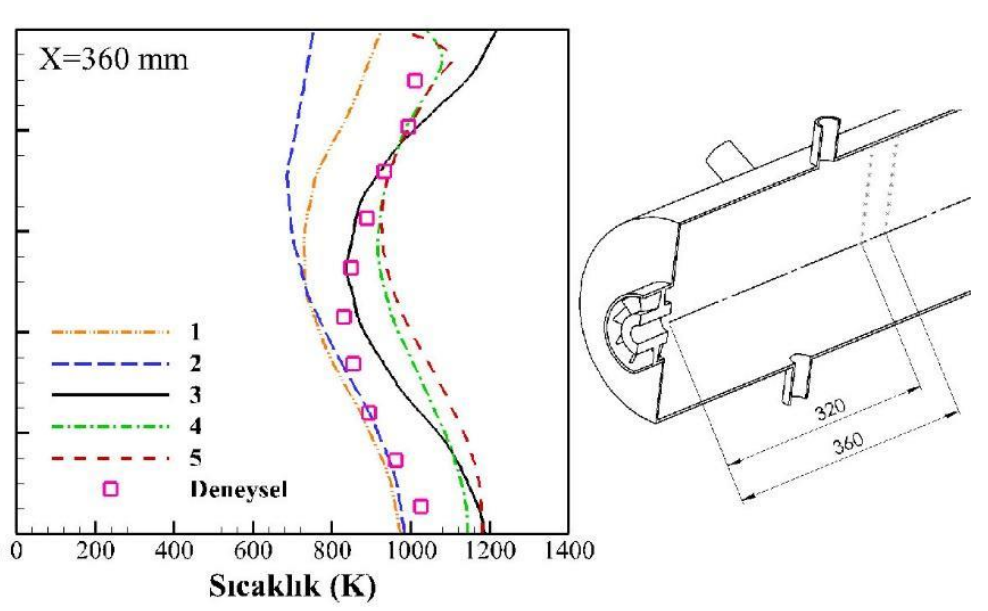

b)

Şekil 4. Döndürücü çıkış radyal sıcaklık dağılımı a) 320 mm eksenel uzunluk ve b) 360 mm eksenel uzunluk.

\section{Döndürücü Sonrası Akış Yapısının İncelenmesi}

Oluşturulan 16 farklı döndürücünün sayısal analizi yapılmış ve performansları girdap sayısı cinsinden karşılaştırılmıştır. Şekil 5'te döndürücü çıkış düzleminde sadece hava hattı çıkışındaki girdap sayısının dağılımı sunulmuştur. İlk sıradaki analizler yakıt giriş hattının sonuçlar üzerine etkisini göstermektedir. Hava giriş çapının azaldığı ve arttığı her iki durumda da referans modelden (M04510401950) daha düşük girdap sayıs1 dağılımının oluştuğu tespit edilmiştir. Öte yandan kanat uzunluğunun (ikinci sıra) girdap sayısı dağılımı üzerine önemli etkisinin olduğu görülmektedir. Döndürücü kanat uzunluğu ile girdap sayısının ters orantılı olduğu, kanat boyu kısaldıkça girdap sayısının yükseldiği görülmektedir. Kanat uzunluğunun $20 \mathrm{~mm}$ olduğu (M04510201950) durumda girdap sayısının alan ağırlıklı ortalama değeri 0.667 'dir. Üçüncü sırada ise kanatçık sayısının girdap sayısına etkisi gösterilmektedir. Kanatçık sayısının girdap sayısına etkisi sınırlı ölçüde gerçekleşmektedir. Son olarak sarım açısının sonuçlara etkisi incelenmiştir. Sarım açısının artışı ile girdap sayısının da artış gösterdiği belirlenmiştir. M03010401950, referans döndürücü M04510401950 ve M12010401950 modellerinin çıkış yüzeyindeki alan ağırlıklı ortalama girdap sayısı değeri sirası ile 0.217, 0.328 ve 0.8 olmaktadır. Geometrik parametrelerinin girdap sayısına olan etkisi referans model ile karşılaştırmalı olarak Şekil 6'da sunulmuştur. Bu şekilde de görüleceği gibi kanat uzunluğu ve sarım açısı girdap sayısını en çok etkileyen parametrelerdir. Şekil 6'da döndürücü çıkışındaki girdap sayısının referans döndürücü çıkışındaki girdap sayısına oranları verilmiştir. Kanat sayısının artışı ile girdap sayısı oranlarında çok küçük değişimler meydana gelmiş ve 1'e yakın değerler elde edilmiştir. Girdap sayısı oranı değeri referans döndürücüye kadar azalırken sonrasında bu oranda yükseliş sergilemiştir. M04506401950 (hatırlatmak gerekirse $\theta=45^{\circ}, \mathrm{n}=6, \mathrm{~L}=40 \mathrm{~mm}, \mathrm{D}_{2}=19.50$ $\mathrm{mm})$ ve M04514401950 döndürücü modellerinde girdap sayıs1 oranları sırası ile 1.028, 1.024'tür. Kanat uzunluğunun değişimi ile hava döndürücüye daha yüksek kanat açılarında girmektedir. Kanat uzunluğunun artışı ile girdap sayısı oranında sürekli bir azalma meydana gelmiştir. M04510201950 modelinde hava döndürücüye diğer modellere göre çok daha yüksek açılarda giriş yapmaktadır. $\mathrm{Bu}$ nedenle kanat uzunluğunun girdap sayısı üzerine etkisi irdelendiğinde en yüksek girdap sayıs1 oranı M04510201950 modelinde olduğu görülmüştür. M04510201950 ve M04510801950 modellerinde girdap sayısı oranları sırası ile 2.033 ve 0.501 olmuştur.

Sarım açısındaki artış girdap sayısı oranı ile artma eğilimindedir. M03010401950 modeli çıkışında referans döndürücüye göre daha düşük girdap sayısı bulunmuştur. M03010401950 ve M12010401950 modellerindeki girdap sayısı oranları sırası ile 0.661 ve 2.438 olmuştur. Görüldüğü üzere M04510201950 modeline göre M12010401950 modelinde daha yüksek girdap sayıs1 oranına ulaşılmış ve bu değer tüm döndürücüler bazında en yüksek girdap sayısı oranı olarak tespit edilmiştir. Yakıt giriş çapındaki değişim ile referans döndürücüye kadar girdap sayısı oranı artış sergilemiş ve sonrasında ise girdap sayısında azamalar başlamıştır. M04510202925 modelinden itibaren yakıt giriş çapının artırılması girdap sayısını oldukça düşürmüştür. M04510400975 ve M04510403900 için girdap sayıs1 oranları sırası ile 0.671 ve 0.664 olarak hesaplanmıştır.

Sarım açısı da girdap sayısı oranı ile artma eğilimindedir. M03010401950 modeli çıkışında referans döndürücüye göre daha düşük girdap sayısı görülmüştür. M03010401950 ve M12010401950 modellerindeki girdap sayıs1 oranları sirası ile 0.666 ve 2.504 bulunmuştur. M04510201950 modeline göre M12010401950 modelinde daha yüksek girdap sayıs1 oranına ulaşılmış ve bu değer tüm döndürücüler bazında en yüksek girdap sayısı oranı olmuştur.

Yakıt giriş çapındaki değişim ile referans döndürücüye kadar girdap sayısı oranı artış sergilemiş ve sonrasında ise girdap sayısında azalmalar başlamıştır. M04510202925 modelinden itibaren yakıt giriş çapının artırılması girdap sayısında küçük azalmalara neden olmuştur. M04510400975 ve M04510403900 girdap 
sayıs1 oranları sirası ile 0.657 ve 0.644 olarak hesaplanmıştır. Döndürücüler sonrası girdap sayısı değerinin 0.6'dan yüksek olması durumunda akıştaki girdabın güçlü, 0.4 'den düşük olması halinde zayıf girdap yapısının oluştuğu kabul edilmektedir (Lefebvre ve Ballal, 2010). Sabit eşdeğerlilik oranında kanat üzerinde yapılan değişimler döndürücü çıkışındaki girdap sayısı dağılımını büyük oranda etkilemiştir. Kanat sarım açısındaki artış döndürücü çıkışındaki teğetsel hızın artışına, kanat uzunluğundaki artış ise teğetsel hızın azalmasına neden olmuştur. Sarım açısının $60^{\circ}$ ve daha yüksek olduğu modellerde kritik girdap sayısı değeri aşılmıştır $\left(\mathrm{S}_{\mathrm{N}}>0.4\right)$. Kanat uzunluğunun $40 \mathrm{~mm}$ 'den düşük olması ve kanat sarım açısının $90^{\circ}$ 'den yüksek olan döndürücü modellerinde güçlü girdaplı akışın oluştuğu $\left(\mathrm{S}_{\mathrm{N}}>0.6\right)$ belirlenmiştir. Bununla beraber diğer modellerde zayıf girdaplı akış meydana gelmiştir

$\mathrm{S}_{\mathrm{n}}$

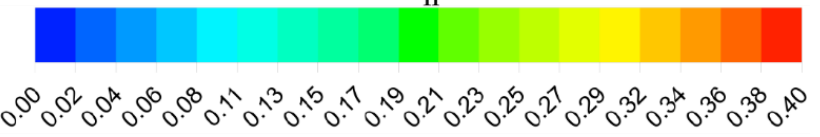

Yakıt Giriş Çapı Değişiminin Etkileri

M04510400975 M04510401950 M04510403900

Kanat Uzunluğu Değişiminin Etkileri

M04510201950 M04510401950 M04510601950

Kanat Sayısı Değişiminin Etkileri

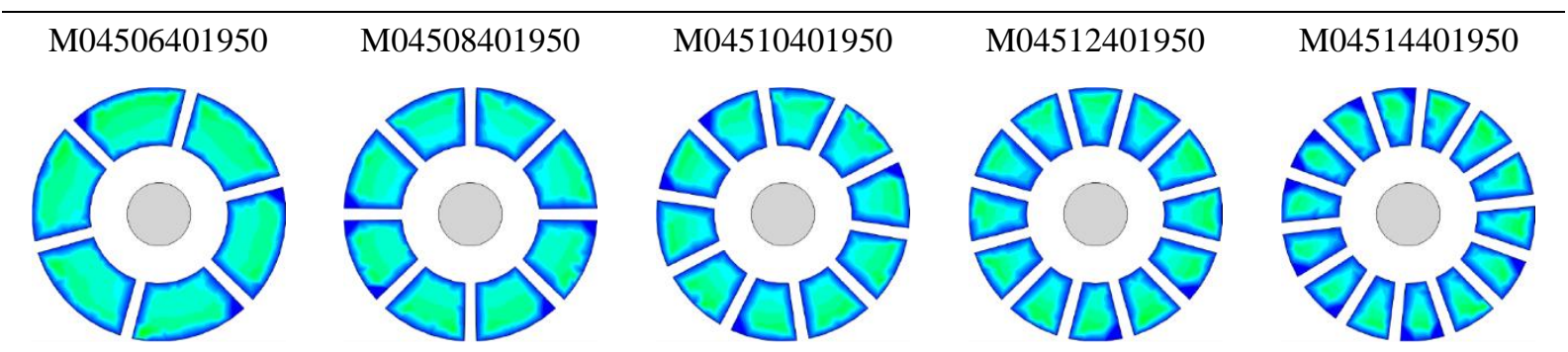

Kanat Sarım Açısı Değişiminin Etkileri

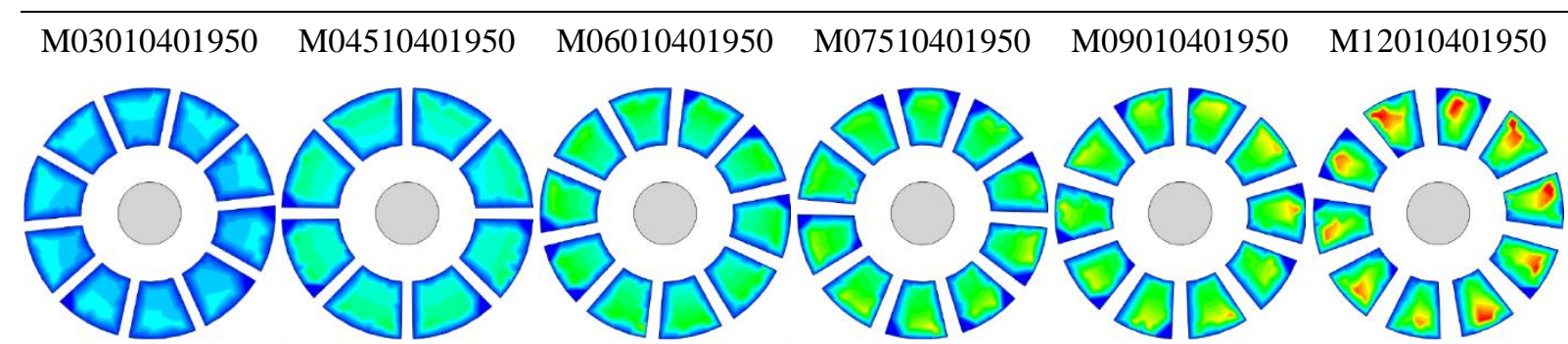

Şekil 5. Döndürücü çıkışındaki girdap sayısının değişimi. 


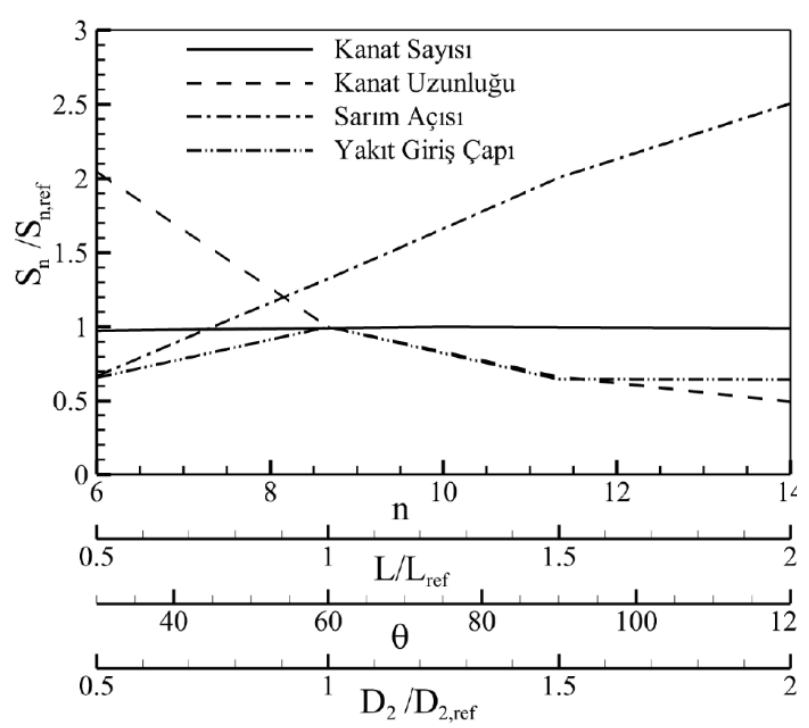

Şekil 6. Döndürücü çıkışındaki girdap sayısı dağılımı.

Yakıt ve hava karışımını karakterize eden parametrelerden bir tanesi de seyreltme bölgesi öncesi türbülans yoğunluğudur. Türbülans yoğunluğu dağılımı, yanmanın kararlılığ 1 ve karışımın homojenitesi hakkında bilgi verebilir. Yanma odasının uzunluğu $\left(\mathrm{L}_{\mathrm{CC}}\right) 2 \mathrm{~m}$ ve yarıçapı (R) 0.105 m'dir. Referans alınan döndürücü geometrisinde yanma reaksiyonunun genelde $0<\mathrm{L}_{\mathrm{R}}<0.1$ $\mathrm{m}$ aralığında oluştuğu belirlenmiştir. $\mathrm{Bu}$ sebeple türbülans yoğunluğu dağılımları döndürücü çıkışından $0.02 \mathrm{~m}, 0.04 \mathrm{~m}, 0.06 \mathrm{~m}$ ve $0.1 \mathrm{~m}$ mesafede $\left(\mathrm{L}_{\mathrm{R}}\right)$ irdelenmiştir. Şekil 7'de görüldüğü üzere $\mathrm{L}_{\mathrm{R}} / \mathrm{L}_{\mathrm{CC}}=0.01$ aralığında radyal eksen boyunca benzer ve simetrik bir türbülans yoğunluğu dağılımı oluşmaktadır. Döndürücünün etkisini incelemek için $-0.37<\mathrm{r} / \mathrm{R}<0.37$ aralığına bakıldığında ani artışlar göze çarpmaktadır. Bu durum yakıt ve havanın döndürücü sonrası karışımını sergileyen bir oluşumdur. M06010401950 modeli için en yüksek türbülansın oluştuğu ve $\mathrm{r} / \mathrm{R}=0.5$ noktasında türbülans yoğunluğunun $\% 20$ değerlerine yükseldiği görülmektedir. Bununla birlikte M03010401950 ve M04510401950 modelleri için yanma odalarında benzer dağılımların olduğu ve en düşük türbülans yoğunluğunun bu döndürücüler ile oluştuğu belirlenmiştir. Kanat sayısı ile türbülans yoğunluğu değişimi incelendiğinde yine simetrik bir dağılım görülmektedir. $-0.37<\mathrm{r} / \mathrm{R}<0.37$ aralığında döndürücünün etkisi ile türbülansta ani artışlar meydana gelmektedir. En düşük türbülans yoğunluğunun M04510401950 modelinde, en yükseğinin ise M04512401950 ve M04514401950 modellerinde oluştuğu görülebilir. Döndürücü geometrileri tasarlanırken kanat uzunluğunun değişimi neticesinde döndürücü kanat giriş açısı da değişmiştir. Referans alınan döndürücü uzunluğuna göre daha kısa döndürücüler yüksek kanat giriş açısına, uzun döndürücüler ise düşük kanat giriş açılarına sahip olmaktadır. Bu durum Şekil 5 'te verildiği üzere girdap sayısının M04510201950 modelinde en yüksek değer elde edildiğinin de kanıtıdır. Döndürücü çıkışında havanın artan teğetsel ve eksenel hızı ile Şekil 7'de de görüldüğü üzere diğer döndürücülere göre türbülans yoğunluğu artmıştır. M04510201950 modeli ile yakıt ve hava karışımının türbülans yoğunluğu $-0.37<\mathrm{r} / \mathrm{R}<0.37$ aralığında \%30 olduğu görülmektedir. Yanma reaksiyonu ile bu değer \%40'ın üzerine çıkmıştır. M04510601950 ve M04510801950 modellerinde düşük kanat açısı ile döndürücüye giriş yapan havanın döndürücü sonrası M04510201950 ve M04510401950 modellerine göre daha düşük türbülans yoğunluğu bulunmuştur. Yakıt giriş çapının değiştirilmesi, dağılımının simetrik yapısını nerdeyse hiç etkilememiştir. M04510400975 modelinde en düşük değerler elde edilirken, en yüksek değerler M04510402925 ve M04510403900 modellerinde görülmüştür. Özellikle $-0.37<\mathrm{r} / \mathrm{R}<0.37$ aralığında M04510403900 modelinde diğer döndürücülere göre büyük artışlar gözlemlenmiş ve \%34 türbülans yoğunluğu seviyelerine ulaşılmıştır.

$\mathrm{L}_{\mathrm{R}} / \mathrm{L}_{\mathrm{CC}}=0.02$ bölgesinde radyal eksende simetrik yapının kaybolduğu görülebilir. $\mathrm{Bu}$ düzlemdeki türbülans yoğunluğu dağılımı $\mathrm{L}_{\mathrm{R}} / \mathrm{L}_{\mathrm{CC}}=0.01$ düzlemindekine göre daha yüksektir. M12010401950 (hatırlatmak gerekirse $\theta=120^{\circ}, \mathrm{n}=10, \mathrm{~L}=40 \mathrm{~mm}, \mathrm{D}_{2}=19.50 \mathrm{~mm}$ ) modelinde daha yüksek türbülans oluşmaktadır. $\mathrm{Bu}$ düzlem üzerinde $0<\mathrm{r} / \mathrm{R}<0.37 \quad$ ve $\quad-0.5<\mathrm{r} / \mathrm{R}<0.7 \quad$ aralıklarında M12010401950 modelinde türbülans yoğunluğu \% 24 değerine kadar ulaşmıştır. Diğer döndürücülerde yakın değerler elde edilmiştir. $\mathrm{L}_{\mathrm{R}} / \mathrm{L}_{\mathrm{CC}}=0.02$ düzleminde en düşük değerlerin M04510401950 modelinde elde edildiği belirlenmiștir. En yüksek türbülans M04512401950 ve M04514401950 modellerinde görülmüş olup yoğunluğu $\% 25^{\prime} \mathrm{e}$ kadar yükselmiştir. $\mathrm{L}_{\mathrm{R}} / \mathrm{L}_{\mathrm{CC}}=0.01$ düzlemine göre $\mathrm{L}_{\mathrm{R}} / \mathrm{L}_{\mathrm{CC}}=0.02$ düzleminde kanat sayısının etkisi daha belirginleşmiş ve M04510401950 modeline göre çok daha büyük artışlar gözlemlenmiştir. $\mathrm{L}_{\mathrm{R}} / \mathrm{L}_{\mathrm{CC}}=0.02$ düzleminde $\mathrm{L}_{\mathrm{R}} / \mathrm{L}_{\mathrm{CC}}=0.01$ düzleminde olduğu gibi M04510201950 modeli için $0<\mathrm{r} / \mathrm{R}<0.37$ ve $-0.5<\mathrm{r} / \mathrm{R}<0.7$ aralıklarında diğer döndürücülere göre yüksek artışlar meydana gelmiştir. M04510201950 modelinde türbülans yoğunluğu \%34 olup $\mathrm{L}_{\mathrm{R}} / \mathrm{L}_{\mathrm{CC}}=0.01$ düzlemine göre daha düşük bir seviyeye inmiştir. $\quad \mathrm{L}_{\mathrm{R}} / \mathrm{L}_{\mathrm{CC}}=0.02$ düzleminde M04510400975 ve M04510401950 modellerinde yakın değerler elde edilmiştir. M04510402925 ve M04510403900 yakıt giriş modellerinde ise daha yüksek değerler görülmüş ve türbülans yoğunluğu \%24 seviyesine ulaşmıştır.

$\mathrm{L}_{\mathrm{R}} / \mathrm{L}_{\mathrm{CC}}=0.03$ ve $\mathrm{L}_{\mathrm{R}} / \mathrm{L}_{\mathrm{CC}}=0.05$ düzlemleri yanmanın geliştiği ve tamamlandığı düzlemler olup Şekil 8 'de görüldüğü üzere $\mathrm{L}_{R} / \mathrm{L}_{C C}=0.01$ ve $\mathrm{L}_{\mathrm{R}} / \mathrm{L}_{\mathrm{CC}}=0.02$ düzlemlerine göre daha yüksek değerlere ulaşılmıştır. Kanat yapısı bu düzlemlerde de etkisini göstermiş ve türbülans yoğunluğunun simetrik dağılımı kaybolmuştur. Genel olarak yakıt ve havanın karışımı, yanma reaksiyonunun gelişimi ve tamamlanma evreleri süresince türbülans yoğunluğu değerlerinde artışların meydana geldiği belirlenmiştir. 

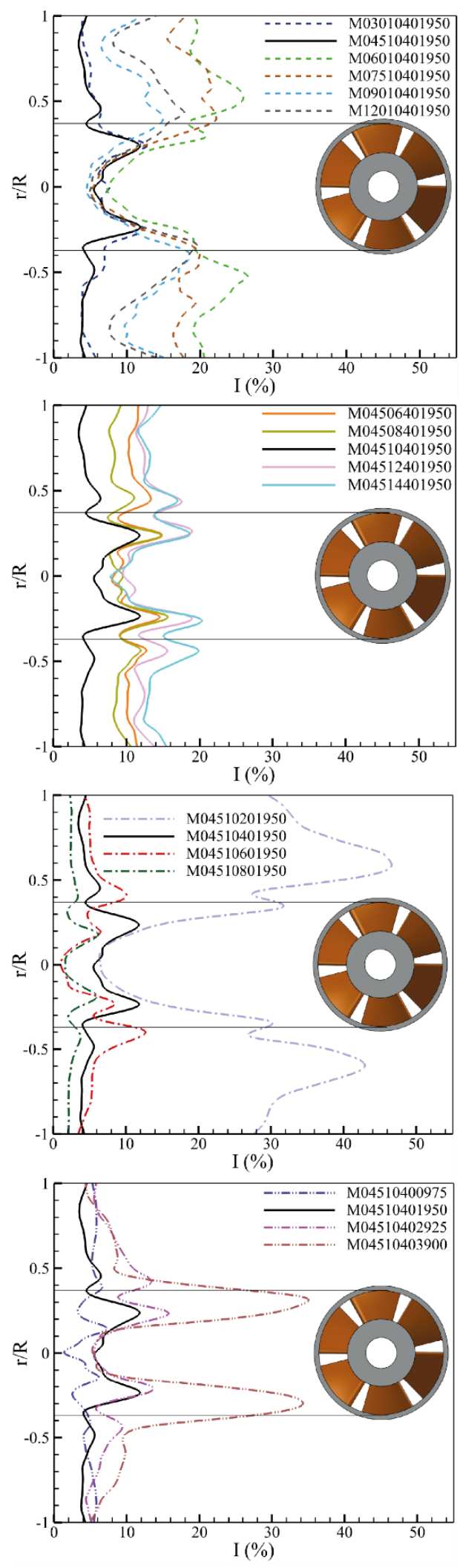

(a)
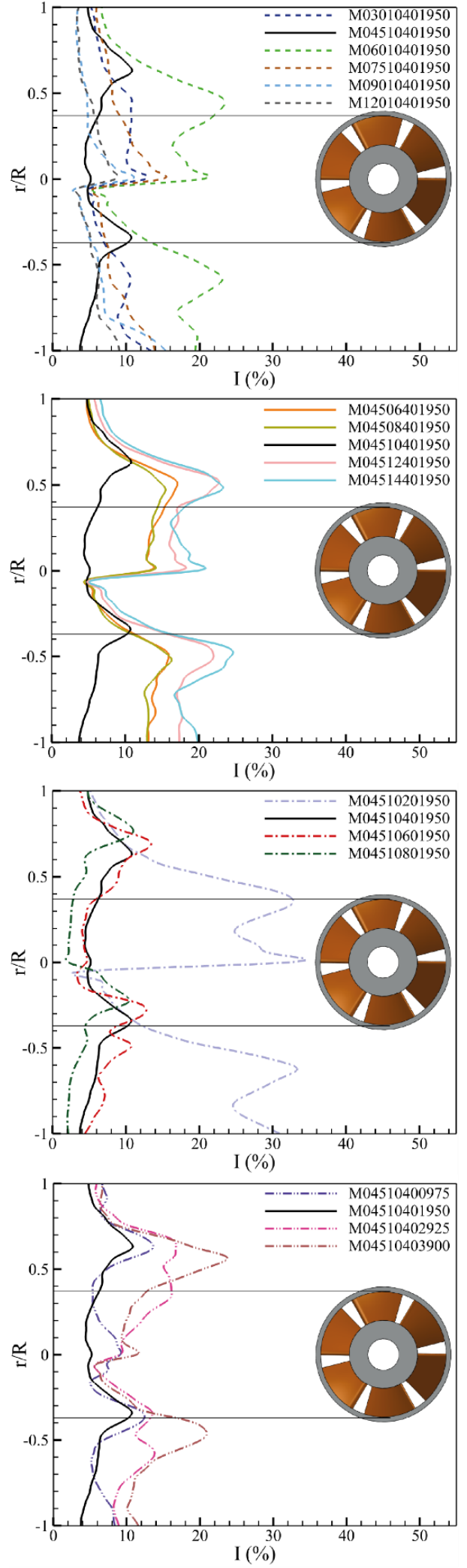

(b)

Şekil 7. a) $\mathrm{L}_{\mathrm{R}} / \mathrm{L}_{\mathrm{CC}}=0.01$ b) $\mathrm{L}_{\mathrm{R}} / \mathrm{L}_{\mathrm{CC}}=0.02$ referans bölgelerinde türbülans yoğunluğu dağılımı. 

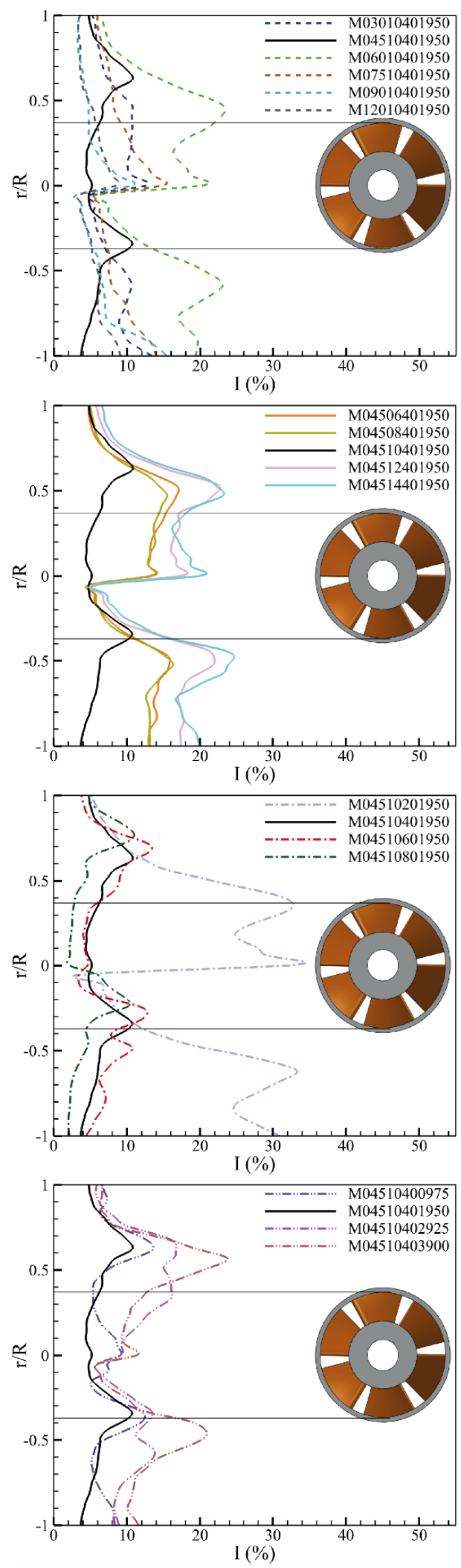

(a)
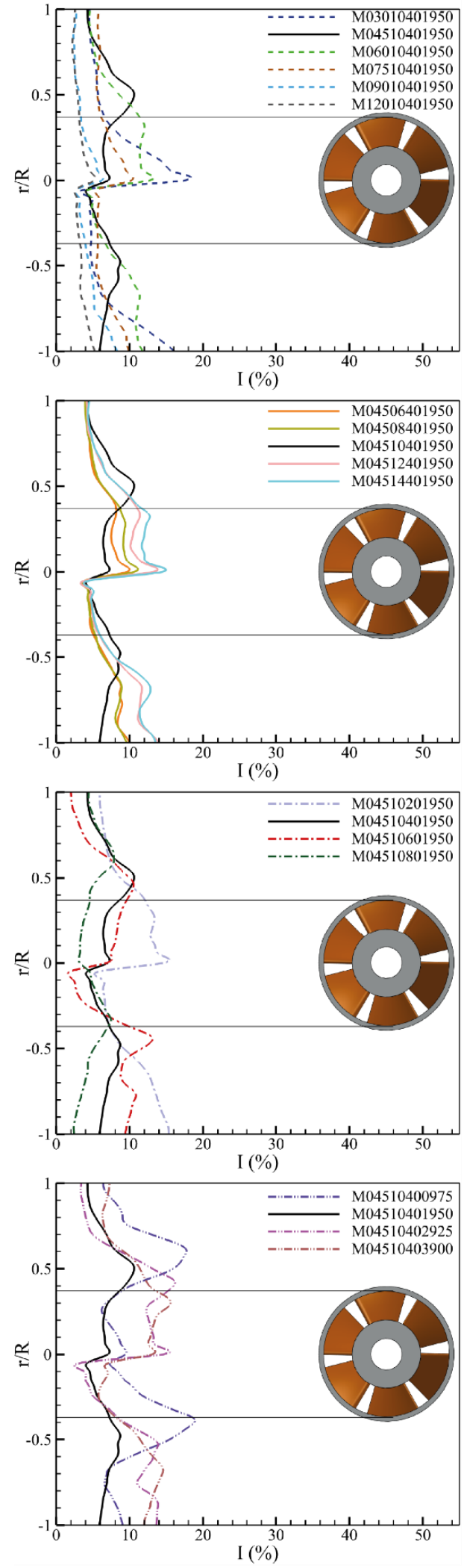

(b)

Şekil 8. a) $\mathrm{L}_{\mathrm{R}} / \mathrm{L}_{C C}=0.03$ b) $\mathrm{L}_{\mathrm{R}} / \mathrm{L}_{C C}=0.05$ referans bölgelerinde türbülans yoğunluğu dağglımı.

Yanma odalarının birincil bölgelerindeki sıcaklık değerleri tam yanma hakkında fikir vermektedir. Bu sebeple Şekil 9'da referans döndürücüde yakıt giriși (a), kanat uzunluğu (b), kanat sayısı (c) ve kanat sarım açısı 
(d) değişimi ile elde edilen sıcaklık oranı dağılımı (ortalama sicaklığın adyabatik sicaklığa göre oranı) verilmiştir. Sabit basınç altında gerçekleşen yanma uygulamalarında, çevre ile bir 1sı ya da iş transferi yok ise reaktanların ve ürünlerin entalpileri eşittir (Mattingly $v d, 2002)$. Bu eşitlik göz önüne alınarak adyabatik alev sicaklığ 1 referans alınan yakıt kompozisyonuna göre (bkz. Tablo 5) $2803 \mathrm{~K}$ olarak hesaplanmıştır. Alev şeklinin, M04510401950 (hatırlatmak gerekirse $\theta=45^{\circ}$, $\mathrm{n}=10, \mathrm{~L}=40 \mathrm{~mm}, \mathrm{D}_{2}=19.50 \mathrm{~mm}$ ) modelindeki kanat sarım açısından büyük durumlar için simetrik yapısını kaybettiği görülmektedir. Kanat sarım açısının değişiminin yanma verimi üzerine etkisi incelendiğinde en yüksek sıcaklık oranının M04510401950 modelinde elde edildiği görülmektedir. Kanat sarım açısının artması sıcaklık değerlerinde azalmaya neden olmaktadır. Seyreltme bölgesi öncesinde, M04510401950 modelinde $\mathrm{T}_{\text {ref }} / \mathrm{T}_{\text {ady }}$ sicaklık oranı 0.793 değerine yükselirken M12010401950 modelinde bu oran 0.722'e kadar düşmektedir.

Kanat sayısının alevin simetrik yapısını bozmadı̆̆ı ve alevin U şekline büründüğü görülmektedir. Yanmanın, kanat sarım açısı çalışmasında olduğu gibi seyreltme bölgesi öncesinde tamamlandiğ 1 belirlenmiştir. M04510401950 modelinde en yüksek $\mathrm{T}_{\text {ref }} / \mathrm{T}_{\text {ady }}$ sicaklık oranının 0.793 değerinde olduğu, M04514401950 modelinde ise bu değerin 0.755 olduğu görülmüştür. Bu sonuçlara göre 10 kanat sayısı için, artan ve azalan kanat sayıları yanma verimini düşürücü nitelikte olduğu düşünülmektedir.

Kanat uzunluğu çalışmasında alevin M04510201950 ve M04510401950 modellerinde simetrik yapısının korunduğu, fakat diğerleri için bu yapının bozulduğu görülmektedir. M04510201950 ve M04510401950 modelleri için sıcaklık değerlerinde artışlar olurken, diğer modellerde sıcaklık değerlerinde düşüşler meydana gelmiştir.

Yakıt giriş çapının yanma üzerine etkisi incelendiğinde M04510403900 modelinde, referans alınan döndürücüye (M04510401950) göre daha yüksek sicaklık değerlerine ulaşıldığ1 görülmektedir. Referans alınan döndürücüden sonra artan yakıt giriş çapının alevin yapısı üzerinde önemli bir etkisinin bulunmadığ 1 belirlenmiştir. M04510400975 modelinde yanmanın seyreltme deliklerine yakın bir bölgede başladığı ve seyreltme deliklerinden gelen havanın yanma gelişmesine engel olduğu tespit edilmiştir. Bu durum M04510400975 modelinde en yüksek $\mathrm{T}_{\text {ref }} / \mathrm{T}_{\text {ady }}$ sicaklık oranının yanma odasında 0.65 'e kadar düşüşüne neden olmuştur. Burada yakıt hattı alanının değişmesine rağmen yakıt debisinin değişmediği unutulmamalıdır. Yakıt hattının alanı azaldıkça yakıtın yanma odasına giriş hızı artmaktadır. Bu durum yakıt hava karışımının sağlanması için gereken zaman diliminde yakıtın döndürücüden daha uzağa taşınmasına sebep olmaktadır. Bu sebeple düşük çaplarda alev oluşumu seyretme deliklerine doğru yaklaşmaktadır. Oysa çap büyüdüğünde yakıt çıkış hızı düşmekte ve yakıt hava ile karışarak hava hızında sürüklenmektedir. Bunun sonucu olarak yanma hep aynı bölgede oluşurken yakıt hızı azaldıkça karışım verimliliği artmaktadır.

Kanat sarım açısının, alevin yapısına ve sıcaklık dağılımına büyük etkisinin olduğu görülmüştür. Benzer şekilde kanat sayısının sıcaklık dağılımına, kanat uzunluğunun ise sıcaklık dağılımı ile birlikte alev yapısına etkisinin olduğu belirlenmiştir. Yakıt giriş çapı ise daha çok yanmanın gerçekleştiği bölgeye tesir etmektedir. Yapılan sayisal analizler sonrası M04510401950 ve M04510403900 modellerinde en yüksek yanma verimi sağlandığı görülmektedir. Şekil 7'de LR/LCC $=0.01$ düzleminde ve $-0.37<\mathrm{r} / \mathrm{R}<0.37$ aralığındaki türbülans yoğunluğu değerinin M04510401950 ve M04510403900 modellerinde \%10 ve $\% 30$ arasında yer aldığı tespiti yapılmıştır.

Eksenel döndürücüler sonrası Şekil 10'da görüldüğü üzere yakıt-havanın karıştığ 1 girdap bölgesi ve ana akım bölgeleri meydana gelmektedir. Girdap bölgesi sonrasında, ters eksenel hız kaybolur ve girdabın etkisindeki azalıș nedeniyle eksenel hız merkeze doğru kayar (Lefebvre ve Ballal, 2010). Şekil 9'da verilen sıcaklık oranları dağılımları incelendiğinde yakıt giriş çapının artışı neticesinde girdap bölgesinin eksenel doğrultuda seyreltme deliklerine yaklaştığ görülmektedir. M04510400975 modelinde yakıtın hızındaki artış nedeniyle hava ile etkileşim döndürücüye çok yakın bir bölgede başlamış ve zayıf bir girdap bölgesi oluşumu meydana gelmiştir. $\mathrm{Bu}$ durumun bir sonucu olarak yüksek sıcaklık bölgeleri seyreltme deliklerine yakın bölgelerde oluşmuştur. Kanat uzunluğunun artışı yakıt giriş çapının değişiminde olduğu gibi girdap bölgelerini seyreltme deliklerine yaklaştırmış ve girdap bölgesi uzunluğunu (radyal eksen boyunca) da azaltmıştır. Kanat sayısı ve kanat sarım açısının artışı benzer etkiler göstermiş ve girdap bölgesi uzunluğunu (radyal eksen boyunca) artırmıştır. 


\section{$\mathrm{T}_{\text {ref }} / \mathrm{T}_{\mathrm{ady}}$

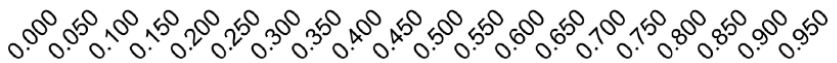

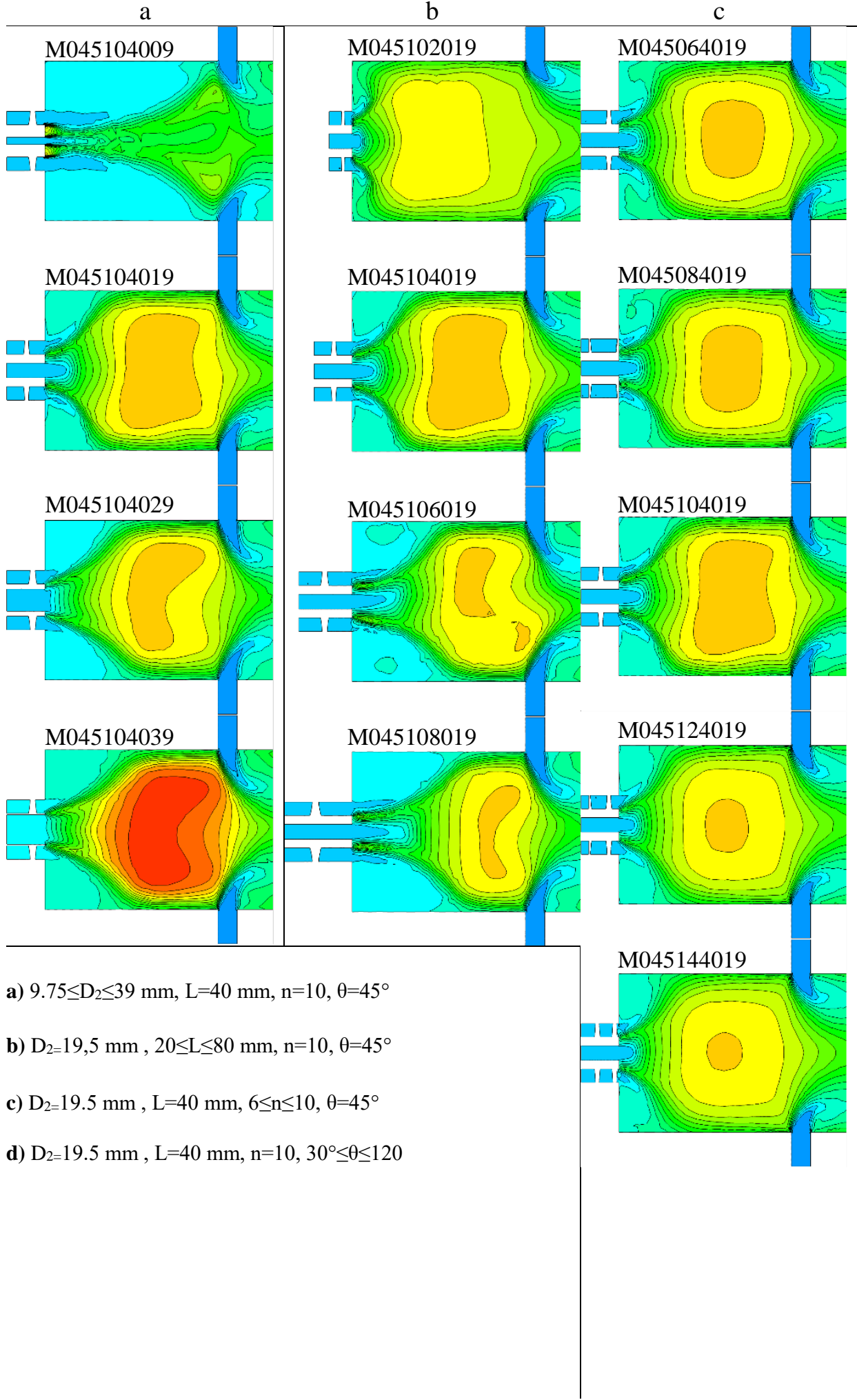

Şekil 9. Yanma odalarında ortalama sıcaklık dağılımları.

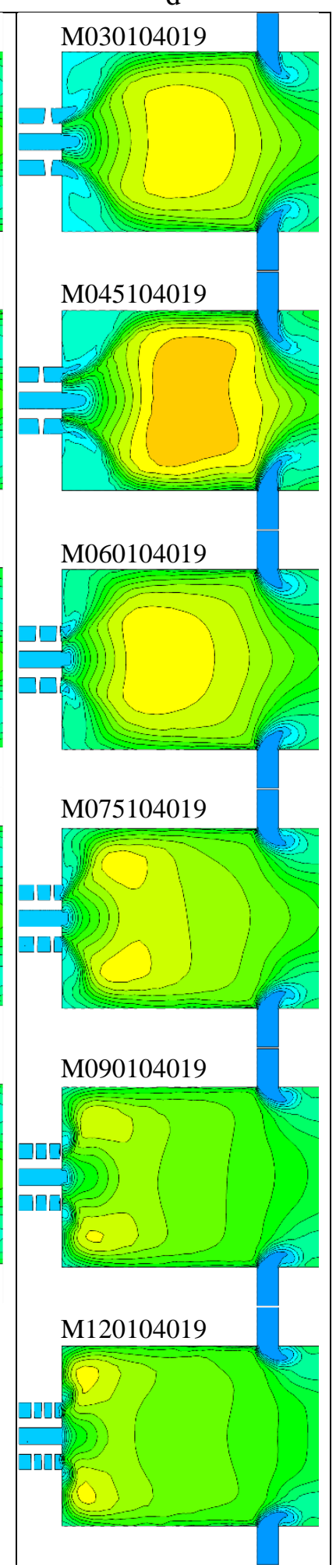




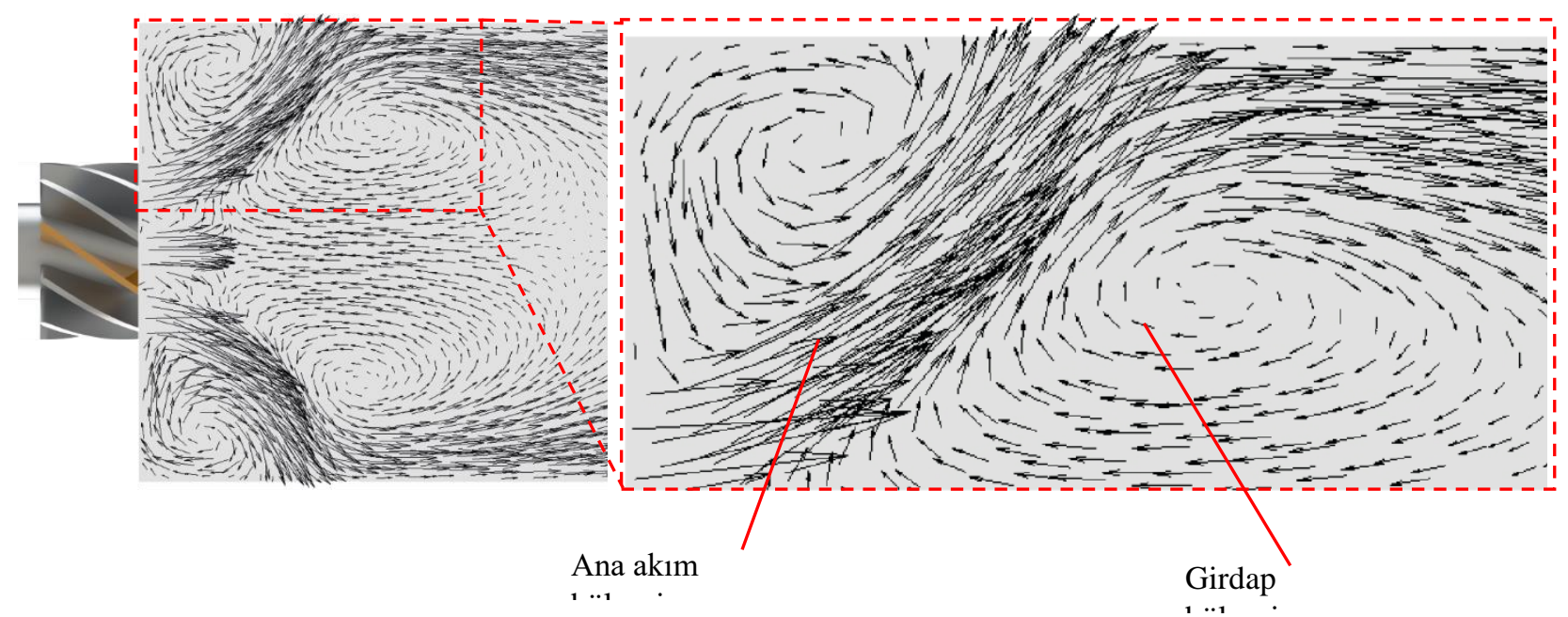

Şekil 10. Girdap akım alanı.

\section{Döndürücü Sonrası Emisyon Gazları Dağılımlarının İncelenmesi}

Yanmayı karakterize eden parametrelerden bir tanesi de CO kütlesel fraksiyonudur. CO kütle fraksiyonun artışının yanma verimini olumsuz yönde etkilediği bilinmektedir (Yihua $v d, 2019$ ). Yanma odalarında yanma reaksiyonları sonrası $\mathrm{CO}$ ve $\mathrm{CO}_{2}$ döngüsünün devamlılığı ve $\mathrm{CO}$ miktarının yanma sonrası azaltılması hedeflenmektedir.

$\mathrm{CO}$ ve $\mathrm{CO}_{2}$ döngüsünün anlaşılması için yanmanın gerçekleştiği bölgede CO kütle fraksiyonu dağılımına bakmak gerekir. Yapılan zamana dayalı çözümlemelerde Şekil 11'de referans döndürücüde yakıt girişi (a), kanat uzunluğu (b), kanat sayısı (c) ve kanat sarım açısı (d) değişimi ile birincil bölgede $\mathrm{CO}$ kütle fraksiyonları dağılımları verilmiștir. Döndürücü sonrası yanma reaksiyonları başlamakta ve CO kütle fraksiyonlarında artışlar meydana gelmektedir. Kanat sarım açısı CO kütle fraksiyonun dağılımını önemli ölçüde etkilemiştir. M04510401950 (hatırlatmak gerekirse $\theta=45^{\circ}, \mathrm{n}=10, \mathrm{~L}=40 \mathrm{~mm}, \mathrm{D}_{2}=19.50 \mathrm{~mm}$ ) modelinde $\mathrm{CO}$ kütle fraksiyonun 0.098 değerine kadar ulaştığı görülmektedir. $45^{\circ}$ sarım açısından büyük sarım açılarında ise CO oluşumu azalmaktadır. En düşük CO kütle fraksiyonu M06010401950 modelinde elde edilmektedir. $\mathrm{CO}_{2}$ oluşumu; 6-10 kanat sayısı arsında artmış, 10 kanat sayısından sonra azalmıştır. En yüksek $\mathrm{CO}$ ve $\mathrm{CO}_{2}$ kütle fraksiyonu M04510401950 modelinde ortaya çıkmaktadır. Farklı kanat uzunluğuna sahip döndürücüler için yapılan sayısal çalışmalar neticesinde döndürücü modellerinde $\mathrm{CO}$ kütle fraksiyonunda yakın değerler elde edilmiştir. Yakıt giriş çapının değişimi ile M04510403900 modelinde en yüksek $\mathrm{CO}$ kütle fraksiyonu elde edilmiş ve 0.098 sınırını aşılmıştır. CO kütle fraksiyonu dağılımı ile alev ve yanmanın simetrik yapısı da belirlenebilmektedir. $45^{\circ}$ kanat sarım açısından büyük kanat sarım açısı ile yanmanın daha küçük bir bölgede gerçekleştiği ve kanat sarım açısının yanmanın simetrik yapısını etkilemediği görülmüştür. Kanat sayısı değişiminin de alev yapısına önemli ölçüde etki etmediği ve bu yapının korunduğu belirlenmiştir. Bununla beraber kanat uzunluğu çalışmasında yalnızca M04510601950 modelinde alev şeklinin değiştiği ve simetrik yapısının kaybolduğu görülmüştür. M04510601950 ve M04510801950 modellerindeki sonuçlara bakıldığında yanmanın daha büyük bir bölgede gerçekleştiği anlaşılmıştır. Yakıt çapının değişmesi yanmanın simetrik yapısını etkilememiştir. Yalnı M04510400975 modelinde $\mathrm{CO}$ ve $\mathrm{CO}_{2}$ döngüsündeki verimsizlik $\mathrm{CO}$ dağılımı ile daha net görülmektedir. Şekil 12'de çizgisel olarak yanma odasının merkez ekseninden geçen $\mathrm{CO}$ kütle fraksiyonları ve sicaklık değerlerinin 5000 zaman adımı için alınmış zaman ortalamaları verilmişsir. CO kütle fraksiyonu dağılımlarına göre M09010401950 ve M12010401950 modelleri için yanmanın $\mathrm{L}_{\mathrm{R}} / \mathrm{L}_{\mathrm{CC}}=0.01$ civarında başladığ 1 ve $\mathrm{L}_{\mathrm{R}} / \mathrm{L}_{\mathrm{CC}}=0.02$ 'e kadar devam ettiği görülmektedir. Referans alınan döndürücüye göre yanma, $\mathrm{L}_{\mathrm{R}} / \mathrm{L}_{\mathrm{CC}}=0.025$ civarında başlamakta ve $\mathrm{L}_{\mathrm{R}} / \mathrm{L}_{\mathrm{CC}}=0.07$ 'e kadar tamamlanmaktadır. $\mathrm{CO}$ kütle fraksiyonun M09010401950 ve M12010401950 modellerinde $\quad \mathrm{L}_{\mathrm{R}} / \mathrm{L}_{\mathrm{CC}}=0.01$ bölgesinden itibaren azalmaktadır. $\mathrm{CO}$ ve $\mathrm{CO}_{2}$ döngüsü, $\mathrm{L}_{\mathrm{R}} / \mathrm{L}_{\mathrm{CC}}=0.03$ bölgesine kadar yeterli sicaklığı varlığ $\breve{l}_{1}$ nedeniyle devam edebilmektedir. Kanat sayısı, sıcaklık ve CO kütle fraksiyonunu neredeyse değiştirmemiştir. Kanat uzunluğu çalışmaları ise M04510201950 modelinde yanmanın $\mathrm{L}_{\mathrm{R}} / \mathrm{L}_{\mathrm{CC}}=0.01$ bölgesinde başladığını göstermektedir. M04510201950 modeli ile meydana gelen ani sıcaklık artışı $\mathrm{CO}$ ve $\mathrm{CO}_{2}$ döngüsünün daha küçük bir bölgede tamamlandığına işaret etmektedir. M04510601950 ve M04510801950 modellerindeki düşük sıcaklık değerleri ise $\mathrm{CO}$ ve $\mathrm{CO}_{2}$ döngüsünün daha uzun bir aralıkta gerçekleşmesine neden olmuştur. M04510403900 modelinde yüksek yanmanın simetrik yapısının bozulmaması ve alev şeklinin korunabilmesi en yüksek sıcaklık değerine ulaşıldığını kanıtlamaktadır. M04510400975 modelinde yakıt hızının yanma reaksiyonu için yüksek oluşu, yanmanın 
$\mathrm{L}_{\mathrm{R}} / \mathrm{L}_{\mathrm{CC}}=0.1$ bölgesine kadar tamamlanamamasına neden olmuştur. Seyreltme deliklerinin etkisi ile sıcaklık değerlerindeki ani düşüş $\mathrm{CO}$ ve $\mathrm{CO}_{2}$ döngüsünü etkilemiş ve birincil bölge çıkışında yüksek CO kütle fraksiyonu ortaya çıkmıştır. CO gibi emisyon gazları çevre sağlığını olumsuz yönde etkilemektedirler. $\mathrm{CO}_{2}$ oluşumdaki $1200 \mathrm{~K}$ üzerindeki artışın, CO mol fraksiyonu değerlerinde düşüşlere sebebiyet vermektedir (Mardani $v d, 2013$ ). Şekil 12 incelendiğinde CO oluşumu $1200 \mathrm{~K}$ 'den sonra azalış eğilimi sergilediği görülebilir.

Ortalama Kütlesel CO Fraksiyonu

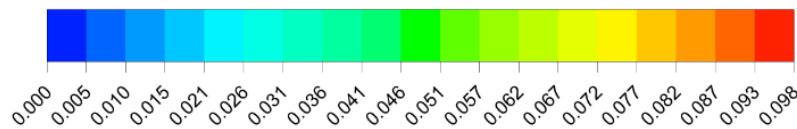

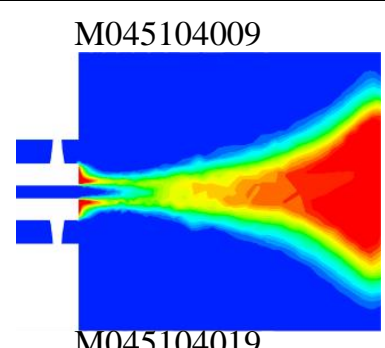

M045104019

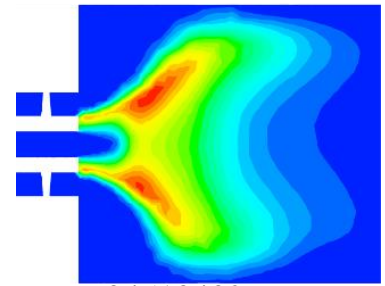

M045104029
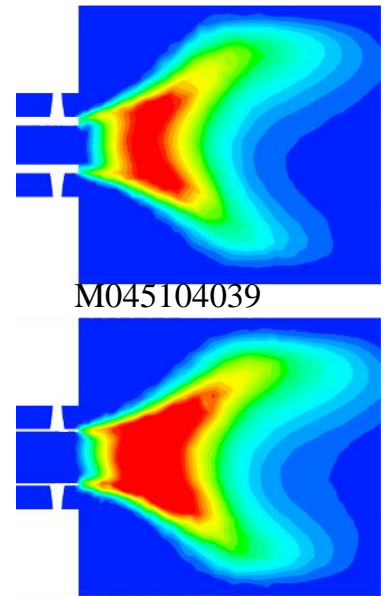

a) $9.75 \leq \mathrm{D}_{2} \leq 39 \mathrm{~mm}, \mathrm{~L}=40 \mathrm{~mm}, \mathrm{n}=10, \theta=45^{\circ}$

b) $\mathrm{D}_{2}=19,5 \mathrm{~mm}, 20 \leq \mathrm{L} \leq 80 \mathrm{~mm}, \mathrm{n}=10, \theta=45^{\circ}$

c) $\mathrm{D}_{2}=19.5 \mathrm{~mm}, \mathrm{~L}=40 \mathrm{~mm}, 6 \leq \mathrm{n} \leq 10, \theta=45^{\circ}$

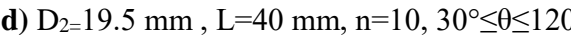

b

c
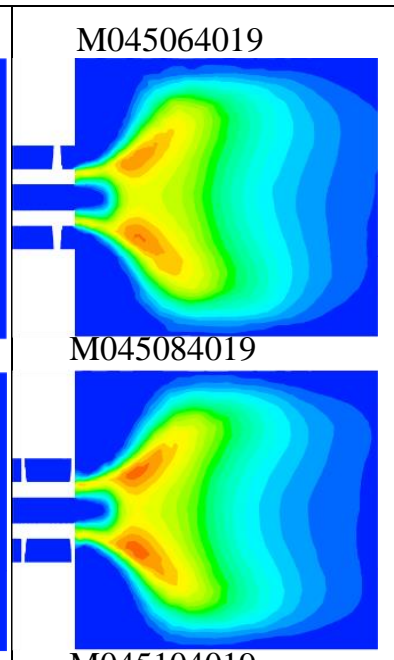

M045106019
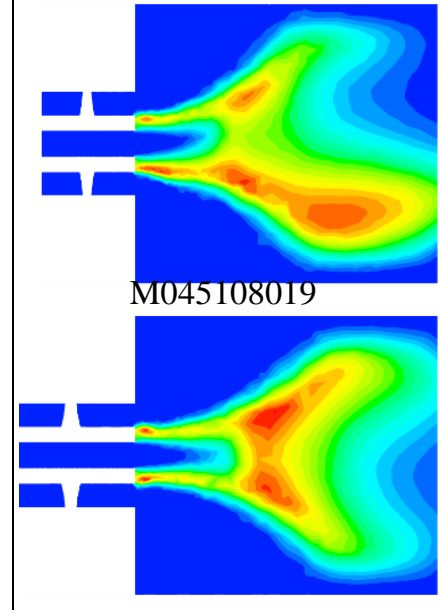

.

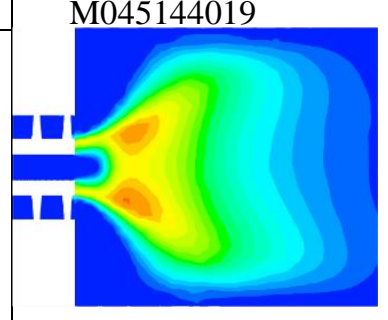

d

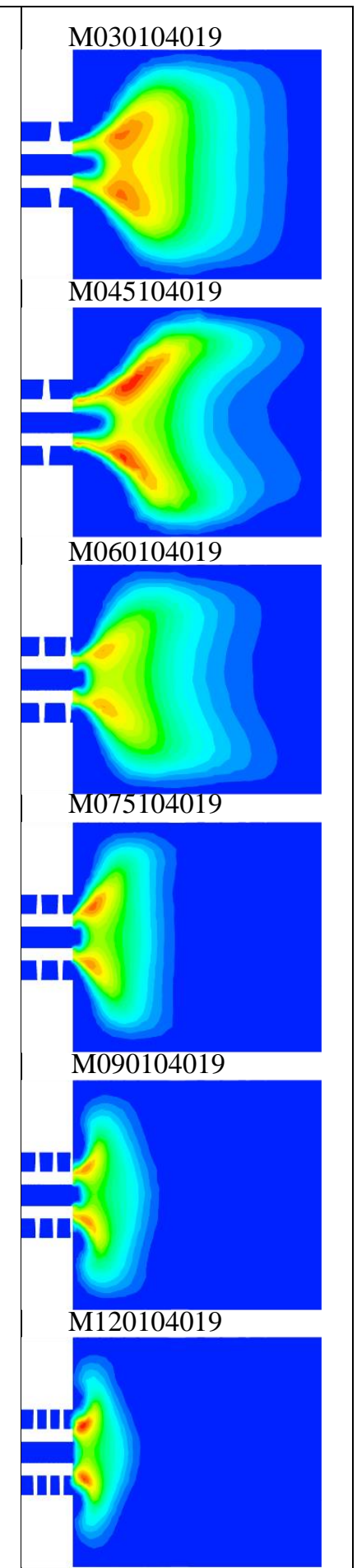

Şekil 11. Yanma odalarında ortalama CO kütle fraksiyonu dağılımları. 

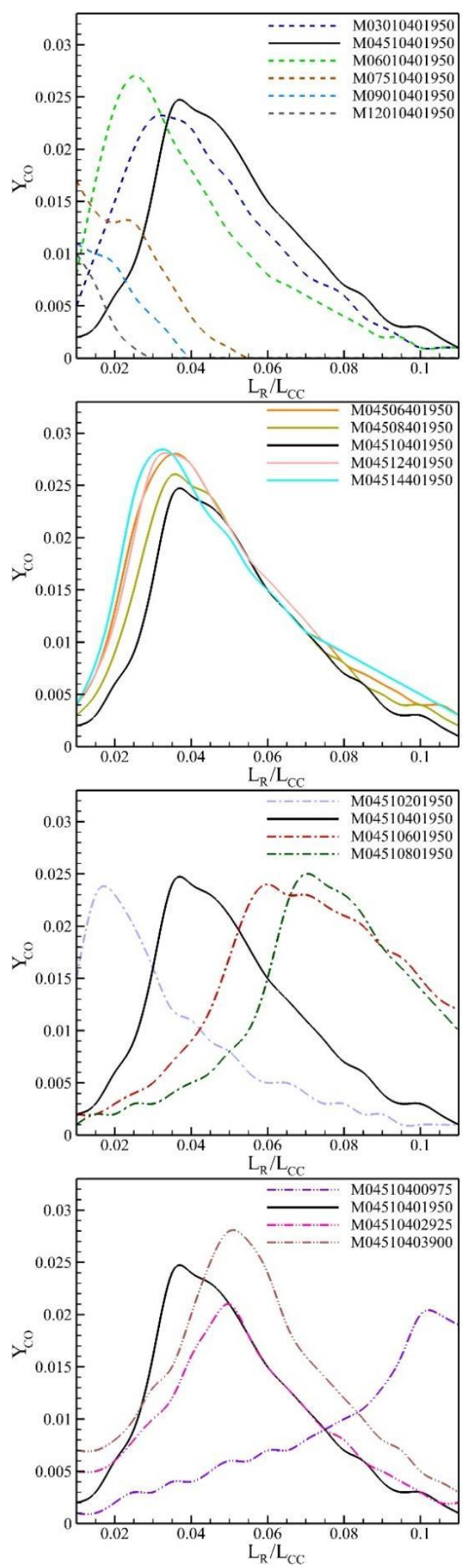

(a)
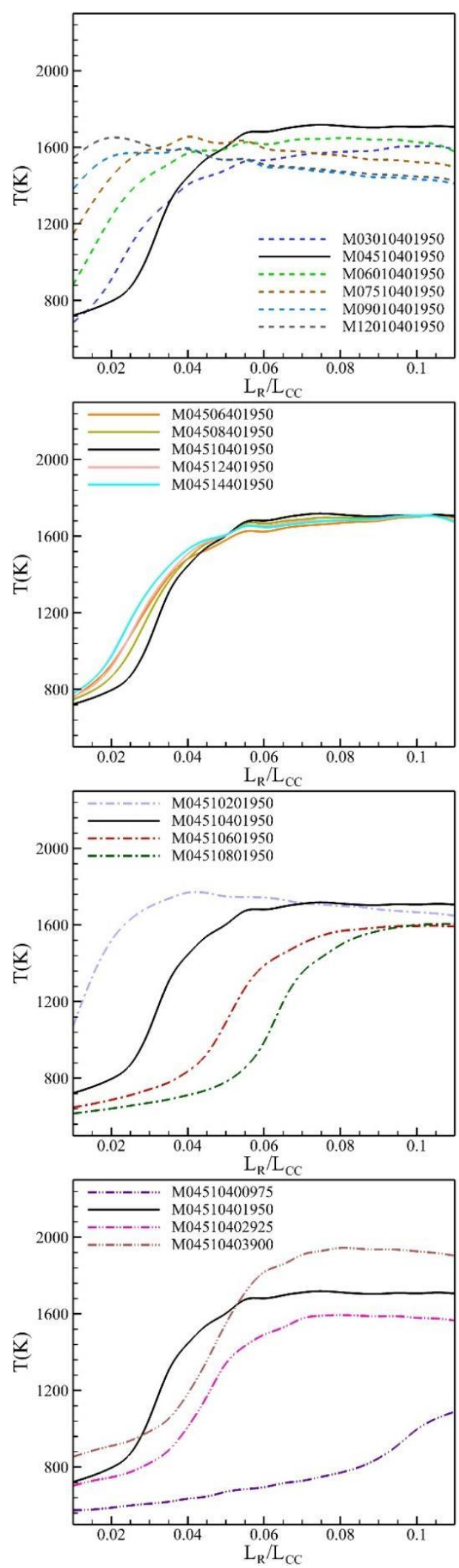

(b)

Şekil 12. Yanma odasında ortalama a) CO kütle fraksiyonu b) sıcaklık değişimi.

Şekil 13'te referans alınan sıcaklık değerinin görüldüğü bölgenin $\left(\mathrm{V}^{*}\right)$ yanma odası bölgesine $\left(\mathrm{V}_{\mathrm{CC}}\right)$ hacimsel oranı verilmiştir. Yüksek sıcaklığın meydana geldiği bölge artışı ile CO oluşumunun daha fazla azaltılabileceği düşünülmektedir. Kanat sayısının değişimi ile yanma odasındaki sıcaklık dağılımı incelendiğinde $1200-2100 \mathrm{~K}$ aralığında döndürücü modellerinde yakın hacim oranlarının meydana geldiği 
görülmektedir. $2100-2250 \mathrm{~K}$ aralığında $\mathrm{V}^{*} / \mathrm{V}_{\mathrm{CC}}$, M04510401950 (bkz. Tablo1) modeline kadar artış göstermiş ve sonrasında artan kanat sayısı ile düşüş eğilimine geçmiştir. Kanat sayısı çalışmasında $\mathrm{V}^{*} / \mathrm{V}_{\mathrm{CC}}$; 2100-2250 K aralığında M04510401950 modelinde \%2.3'e kadar yükselirken, M04514401950 modelinde \%0.14'e kadar düşüş görülmüştür. Sarım açısı çalışmasında 1800-1950 K sicaklık aralığına kadar $\mathrm{V} * / \mathrm{V}_{\mathrm{CC}}$ için yakın değerler elde edilmiştir. 1500-1650 K sıcaklık aralığında M12010401950 modelinde en yüksek $\mathrm{V} * / \mathrm{V}_{\mathrm{CC}}$ elde edilmiștir ve bu değer \%4.98 olarak hesaplanmıştır. $\quad 1950-2100 \mathrm{~K}$ sicaklık aralığına M12010401950 modeline sahip yanma odasinda ulaşılamadığı görülmektedir. 2100-2250 K sıcaklık aralığının ise yalnız M04510401950 modeline sahip yanma odasında elde edilmiştir.

Kanat uzunluğunun değişimi ile yanma odasındaki sıcaklık dağılımı incelendiğinde 1650-1800 K'e kadar yakın değerler elde edildiği ve daha yüksek sıcaklıklarda M04510201950 (hatırlatmak gerekirse $\theta=45^{\circ}, n=10$, $\mathrm{L}=20 \mathrm{~mm}, \mathrm{D}_{2}=19.50 \mathrm{~mm}$ ) modelinde $\mathrm{V} * / \mathrm{V}_{\mathrm{CC}}$ oranında daha yüksek değerlere ulaşılmıştır. 2100-2250 K sıcaklık aralığında kanat uzunluğundaki artış M04510401950 modeline kadar $\mathrm{V}^{*} / \mathrm{V}_{\mathrm{CC}}$ yükselirken daha yüksek kanat uzunluklarında bu oranın düşüş eğilimine geçiş yaptığ görülmektedir. 2100-2250 K sicaklık aralığında en yüksek V*/V $\mathrm{CC}, \mathrm{M} 04510401950$ modelinde elde edilmiş ve bu oran \%2.3 olarak bulunmuştur. Yakıt giriş çapının değişimi ile M04510400975 modeli ile çok düşük sıcaklık dağılımları meydana gelmiștir. $2250 \mathrm{~K}$ 'den daha yüksek sicaklıklar sadece M04510403900 modeli ile elde edilebilmiştir. M04510403900 modeline sahip yanma odasında en yüksek sıcaklık aralıklarında (2550-2700 K) $\mathrm{V} * / \mathrm{V}_{\mathrm{CC}} \% 1.32$ olarak hesaplanmıştır.

Sonuç olarak referans sicaklık değerlerine göre hacim oranları incelendiğinde sarım açısı ve kanat uzunluğu değişimi ile büyük farklılıkların meydana geldiği düşünülmektedir. Yüksek sıcaklıklarda $\left(\mathrm{T}_{\text {ref }} \geq 2100 \mathrm{~K}\right)$ artan sarım açısı ve azalan kanat uzunluğu referans alınan sıcaklığın görüldüğü bölgenin ihmal edilebilir seviyelere kadar düștüğü görülmektedir. $\mathrm{Bu}$ durum $\mathrm{CO}-\mathrm{CO}_{2}$ döngüsünün tamamlanamayıp farklı hidrokarbon ve atık gazı türevlerinin meydana gelmesine yol açabilir.

Yapılan sayısal analizler sonrası $\varphi=0.679$ değerindeki yanma uygulamalarında kanat yapısı üzerine yapılan modifikasyonlar ile CO derişimi azaltılabilirken, döndürücüler ile en yüksek $2250 \mathrm{~K}$ sıcaklıklarına ulaşılabilmiştir. Yakıt giriş çapı üzerine yapılan değişimler sonrası M04510403900 modeline sahip yanma odasında 2550-2700 K sicaklık aralığı elde edilmiş ve yanma verimi artırılabilmiştir.
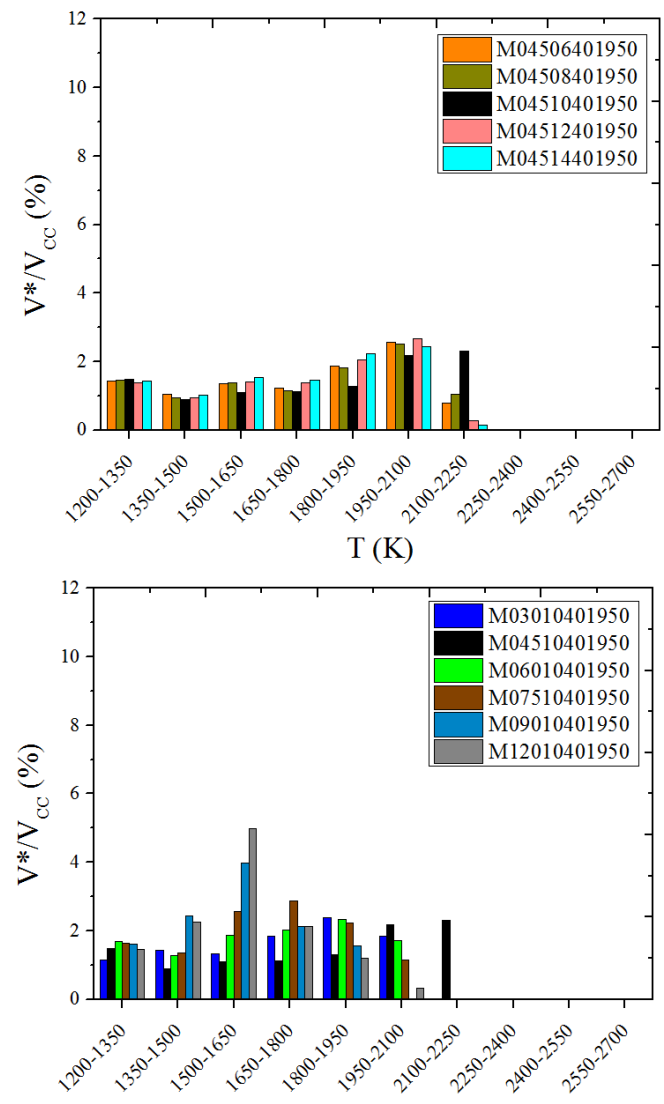

$\mathrm{T}(\mathrm{K})$
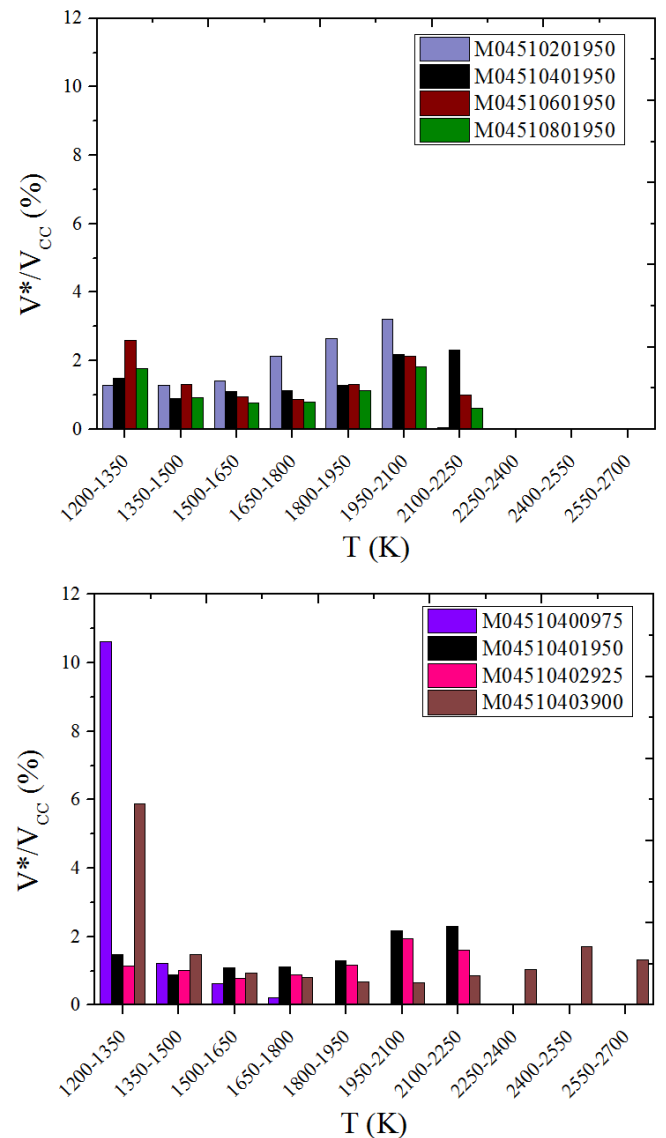

Şekil 13. Farklı sıcaklık değerlerinin döndürücü modellerine göre yanma odasında dağılımı. 
Farklı Eşdeğerlilik Oranlarında Akış Yapısının İncelenmesi

Gaz türbinli motorlar ya da döndürücülerin kullanıldığ uygulamalar düşünüldüğünde farklı yakıt/hava karışım gereksinimi oluşmaktadır. $\mathrm{Bu}$ durum yanma odalarındaki akış yapısını değiştirmektedir. Çalışmanın bu aşamasında; fakir, stokiyometrik ve zengin yanma koşullarında yanma odasındaki akış yapısı incelenmiştir. Referans alınan deneysel çalıșmada fakir oranı $\varphi=0.697$ koşulu için en yüksek değerler elde edilmiştir. Bu bölgede stokiyometrik ve zengin yanma koşullarında çok daha düşük türbülans yoğunluğu dağılımı gerçekleşmiştir. $0.01<\mathrm{L}_{\mathrm{R}} / \mathrm{L}_{\mathrm{CC}}<0.05$ aralığgnda türbülans yoğunluğu dağılımı değişmemiş ve en yüksek türbülans değerleri fakir yanma koşullarında oluşmuştur. Özelikle $\mathrm{L}_{\mathrm{R}} / \mathrm{L}_{\mathrm{CC}}=0.05$ bölgesinde türbülans yoğunluğu dağılımlarının birbirine oldukça yakınlaştığı görülmüştür. Türbülanslı difüzyon alevlerinde büyük ölçekli girdap hareketleri ile reaktanlar makro ölçekte karıştırılır ve sonrasında küçük ölçekli girdaplara aktarılır (Ohtake, 1993). Bu nedenle türbülanslı difüzyon alevlerine türbülans değerlerindeki değişimin etkisi büyüktür. Bu makalede fakir yanma koşullarında $0.01 \leq \mathrm{L}_{\mathrm{R}} / \mathrm{L}_{\mathrm{CC}} \leq 0.02$ ve $0.37<\mathrm{r} / \mathrm{R}<0.37$ aralıklarında yanmanın başladığına dikkat çekilmişti. Yine bu aralıklarda türbülans yoğunluğunun \%34 seviyelerine ulaştığ1 ve \%20 seviyesinin altına düşmediği aktarılmıştı.

bir yanma $\quad(\varphi=0.697)$ gerçekleştirilmiştir. Stokiyometrik ve zengin yanma koşulları için seçilen eşdeğerlilik oranları 1 ve $1.2^{\prime}$ dir. Çalışmada fakir yanma koşulunda en verimli yanmanın gerçekleştiği M04510403900 döndürücü modeli için sayısal çalışmalar yürütülmüştür.

Yakıt-hava karışımı ve yanmanın kararlılığı konusunda önemli bir ölçüt olan türbülans yoğunluğu için Şekil 14'e bakılabilir. $\mathrm{L}_{\mathrm{R}} / \mathrm{L}_{\mathrm{CC}}=0.01$ bölgesinde eşdeğerlilik Stokiyometrik ve zengin yanma koşullarındaki sıcaklık değişimleri, türbülans yoğunluğunun yanma verime üzerine etkisini bir kez daha ortaya koymuştur. Türbülans yanmanın başlangıç bölgelerinde azalmış, bu da yanma veriminin düşmesine sebep olmuştur. Öyle ki fakir yanma koşulundan daha düşük sıcaklık değerleri ile karşılaşılmıştır. Bununla beraber, zengin ve fakir yanma koşullarında yakın sıcaklık dağılımları belirlenmiştir.

Şekil $15^{\prime}$ 'te fakir, stokiyometrik ve zengin yanma koşullarında çizgisel olarak yanma odasının merkez ekseninden geçen CO kütle fraksiyonları ve sıcaklık değerlerinin 5000 zaman adımı için alınmış zaman ortalamaları verilmiştir. $0.01 \leq \mathrm{L}_{\mathrm{R}} / \mathrm{L}_{\mathrm{CC}} \leq 0.02$ bölgesinde CO kütle fraksiyonlarında yakın değerler elde edilmiştir. Zengin karışımın yapısı gereği yanma sonrası daha yüksek CO kütle fraksiyonunun meydana
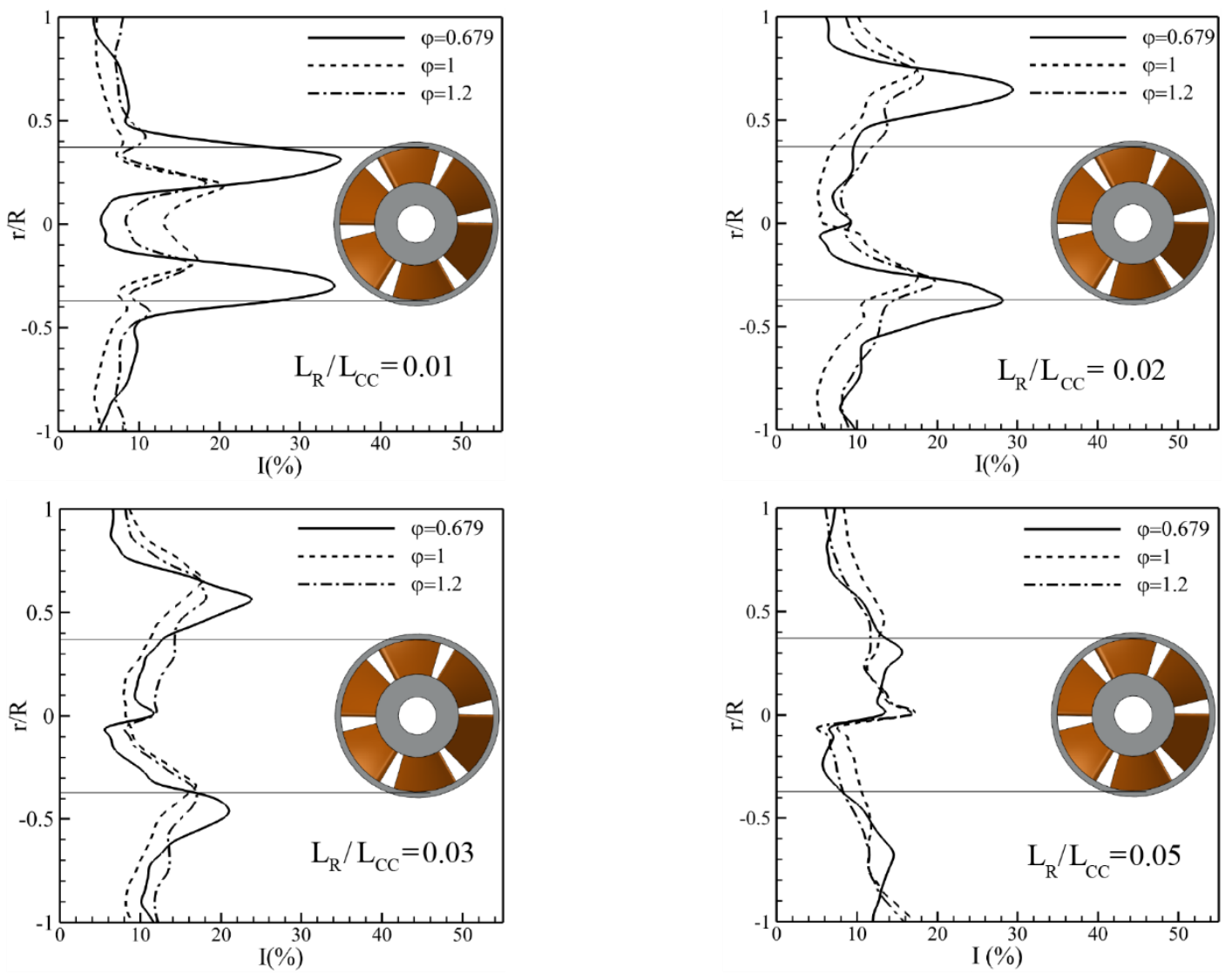

Şekil 14. Farklı eşdeğerlilik oranlarında türbülans yoğunluğu değişimi. 


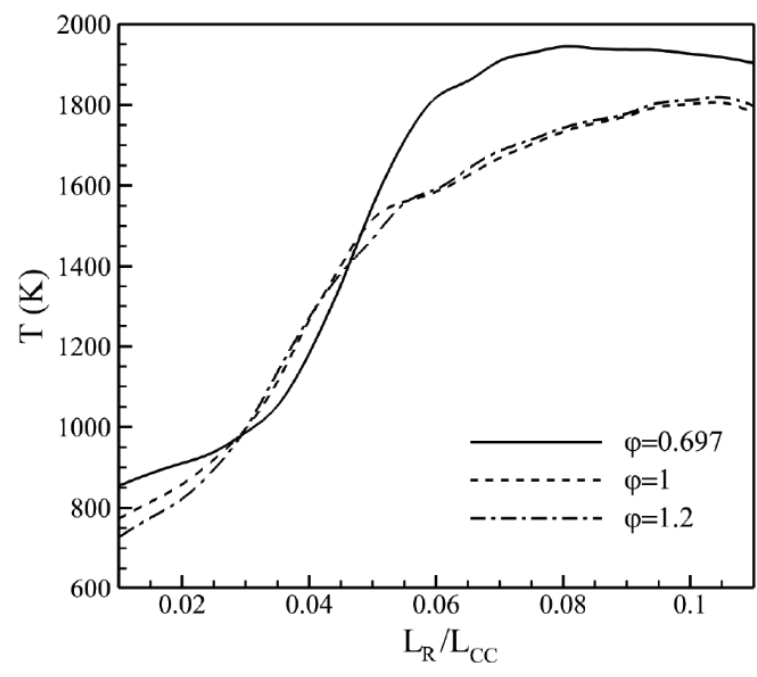

(a)

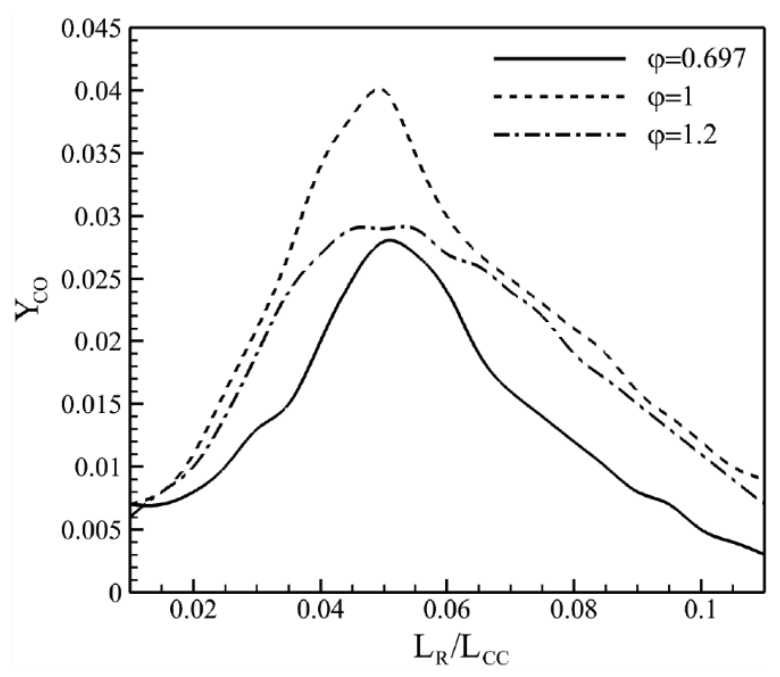

(b)

Şekil 15. Farklı eşdeğerlilik oranlarında a) Sıcaklık b) CO kütle fraksiyonu dağılımı.

geleceği bilinmektedir. Gerek türbülans gerekse girdap sayısı dağılımı nedeniyle stokiyometrik ve zengin yanma koşullarında benzer sıcaklık dağılımları elde edilmiştir. Birincil bölge çıkışındaki $\left(\mathrm{L}_{\mathrm{R}} / \mathrm{L}_{\mathrm{CC}}=0.1\right) \quad \mathrm{CO}$ kütle fraksiyonu değerlerinin zengin ve stokiyometrik yanma koşulları için yakın olması sıcaklık dağılımındaki benzerliğin bir sonucu olduğu düşünülmektedir.

\section{SONUÇLAR}

$\mathrm{Bu}$ çalışmada farklı döndürücü geometrilerin yanma üzerine etkisi incelenmiştir. Çalışmanın ilk aşamasında referans alınan döndürücü yeniden tasarlanmıştır. Referans alınan döndürücü kullanılarak yapılan sayısal ve deneysel çalışmaların sonuçları karşılaştırılmış olup yakın değerlerin elde edilmesiyle sayısal yöntem doğrulanmıştır. İkinci aşamada farklı kanat sarım açısı, kanat sayısı, kanat uzunluğu ve yakıt giriş çapı parametreleri ile 16 yanma geometrisi oluşturulmuştur. Referans alınan döndürücü için yapılan sayısal analizlerindeki türbülans modeli, yanma modeli, aynı sınır şartları ve aynı ayrıklaştırma yöntemleri uygulanarak sayısal analizler tekrarlanmıştır. Bulunan sonuçlar aşağıda verilmiştir.

Yanma sonrası $\mathrm{T}_{\text {ref }} / \mathrm{T}_{\text {ady }}$ sıcaklık oranı dağılımları incelendiğinde $U$ alev şekli ile karşılaşılmıştır. Kanat sarım açısının alev şekli üzerine önemli etkisinin olduğu belirlenmiştir. $75^{\circ}, 90^{\circ}$ ve $120^{\circ}$ sarım açılarında U alev şeklinin tamamen yok olduğu görülmüştür.

Alevin simetrik yapısı üzerine kanat uzunluğunun etkisinin olduğu belirlenmiştir. Özellikle M04510401950 modelinden daha büyük kanat uzunluğuna sahip döndürücülerdeki yanma odalarında alevin simetrik yapısının kaybolduğu görülmüştür. Kanat sayısı, kanat sarım açısı ve yakıt giriş çapının alevin simetrik yapısı üzerine etkisinin düşük olduğu saptanmıştır.

Yakıt giriş hızının artışı ile yanma veriminin yüksek oranda değiştiği, M04510400975 $\left(\theta=45^{\circ}, \mathrm{n}=10, \mathrm{~L}=40\right.$ $\left.\mathrm{mm}, \mathrm{D}_{2}=9.75 \mathrm{~mm}\right)$ modelinde CO kütle fraksiyonu dağılımı ile anlaşılmıştır. M04510400975 modeli sonrası birincil bölge çıkışında CO kütle fraksiyonu değerinin 0.018 olduğu ve referans alınan döndürücüde bu değerin aynı bölgede 0.002 olduğu belirlenmiştir. Bu durum aynı zamanda düşük yakıt çapına sahip döndürücülerde daha yüksek emisyon değerinin elde edileceğini de göstermektedir.

Döndürücü veriminin belirlenebilmesi için yanma odasındaki sıcaklık dağılımları incelenmiştir. Buna göre en yüksek sicaklık dağılımının M04510401950 ve M04510403900 yakıt girişine sahip döndürücü geometrisinde elde edildiği ve yanma odasındaki sıcaklığın 2629 K sıcaklık değerine ulaşılabildiği görülmüştür. Referans alınan döndürücüde ise $2225 \mathrm{~K}$ değerine yakın sonuçlar elde edilmiştir.

Fakir yanma koşullarında en yüksek yanma veriminin M04510403900 modelinde $\left(\theta=45^{\circ}, \mathrm{n}=10, \mathrm{~L}=40 \mathrm{~mm}\right.$, $\mathrm{D}_{2}=39.00 \mathrm{~mm}$ ) elde edilmesi ile stokiyometrik ve zengin yanma koşullarında yanma odasındaki akış yapısının değişimi incelenmiştir. Stokiyometrik ve zengin yanma koşullarında fakir yanmaya göre daha düşük türbülans yoğunluğu elde edilmesi yanma verimini oldukça etkilemiş ve yanma odasındaki sıcaklık değerlerinin sırası ile $138.8 \mathrm{~K}$ ve $125.4 \mathrm{~K}$ azalmasına neden olmuştur.

İleriki çalışmalarda benzer test düzeneğinin kurulması, yeni modelin üretilerek deneysel olarak doğrulamasının yapılması, tasarım uzayının genişletilmesi, analizlerde LES yönteminin kullanılması ve sinir ağları yöntemi ile optimizasyon yapılması planlanmaktadır.

\section{TEŞEKKÜR}

Bu çalışma Eskişehir Teknik Üniversitesi Bilimsel Araştırma Koordinasyon Birimi tarafından (Proje No:19ADP078) desteklenmiştir. 


\section{KAYNAKLAR}

Abubakar Z., Shakeel M. R. and Mokheimer E. M. A., 2018, Experimental and Numerical Analysis of NonPremixed Oxy-Combustion of Hydrogen-Enriched Propane in a Swirl Stabilized Combustor, Energy, 165, 1401-1414.

Eldrainy Y.A., Saqr K. M., Aly H.S. and Mohd Jaafar M. N., 2009, CFD insight of the flow dynamics in a novel swirler for gas turbine combustors, International Communications in Heat and Mass Transfer, 36, 936941.

Hoda A., Rahman T. M. R., Asrar W. and Khan S. A., 2021, A Comparative Study of Natural Gas and Biogas Combustion in A Swirling Flow Gas Turbine Combustor, Combustion Science and Technology, https://doi.org/10.1080/00102202.2021.1882441

İlbaş M., Karyeyen S. and Yilmaz İ., 2016, Effect of swirl number on combustion characteristics of hydrogencontaining fuels in a combustor, International Journal of Hydrogen Energy, 41, 7185-7191.

Jones W. P. and Whitelaw J. H., 1982, Calculation Methods for Reacting Turbulent Flows: A Review, Combustion and Flame. 48, 1-26.

Jeong Y. K., Jeon C. H. and Chang Y. J., 2004, Effects of a Swirling and Recirculating Flow on the Combustion Characteristics in Non-Premixed Flat Flames, KSME International Journal, 18, 499-512.

Kwark J. H., Jeong Y. K., Jeon C. H. and Chang Y. J., 2004, Effect of Swirl Intensity on the Flow and Combustion of a Turbulent Non-Premixed Flat Flame, Flow, Turbulent and Combustion, 73, 231-257.

Launder B. E. and Spalding D. B., 1974, The Numerical Computation of Turbulent Flow, Computer Methods in Applied Mechanics and Engineering, 3, 269-289.

Lefebvre A.H. and Ballal D. R., 2010, Gas Turbine Combustion Alternative Fuels and Emissions, 140-146.

Mardani A., Tabejamaat S. and Hassanpour S., 2013, Numerical Study of $\mathrm{CO}$ and $\mathrm{CO}_{2}$ formation in $\mathrm{CH}_{4} / \mathrm{H}_{2}$ blended flame under MILD condition, Combustion and Flame, 160, 1636-1649.

Mattingly D. J., Heiser W. H. and Pratt D. T., 2002, Aircraft Engine Design, 330-339

Midgley K., Spencer A. and McGuirk J. J., 2005 , Unsteady flow structures in radial swirler fed fuel injectors, Journal of Engineering for Gas Turbines and Power, 127, 755-764.

Ohtake K., 1993, Advanced Combustion Science, 1-7.
Patel V. and Shah R., 2019, Effect of Swirl and Number of Swirler Vanes on Combustion Characteristics of Methane Inverse Diffusion Flame, Journal of Mechanical Science and Technology, 33, 1947-1958.

Poinsot T. and Veynante D., 2005, Theoretical and Numerical Combustion, 313-325.

Pourhoseini H.S. and Asadi R., 2017, An Experimental Study of Optimum Angle of Air Swirler Vanes in Liquid Fuel Burners, Journal of Energy Resources Technology, DOI: $10.1115 / 1.4035023$

Prakash R.S., Santhosh K.S. and Sadanandan R., 2020, Flame Characteristics and Pollutant Emissions of a Nonpremixed Swirl Burner with Annular Swirling Fuel Injection, Recent Asian Search on Thermal and Fluid Sciences, DOI: 10.1007/978-981-15-1892-8_42.

Rajabi V. and Amani E., 2018, A Computational Study of Swirl Number Effects on Entropy Generation in Gas Turbine Combustors, Heat Transfer Engineering, DOI:10.1080/01457632.2018.1429056.

Sayyar A. and Davani A., 2021, Numerical optimization of flame stability in a swirl combustion chamber with helical tapes, Thermal Science and Engineering Progress, https://doi.org/10.1016/j.tsep.2020.100815

Serag-Eldin M. A., and Spaldin D. B., 1979, Computations of Three-Dimensional Gas-Turbine Combustion Chamber Flows, The American Society of Mechanical Engineers, 101, 326-336.

Shah R. D., 2015, Thermal and Emission Characteristics of a Can Combustor, Heat Mass Transfer, 52, 499-509.

Shahin I., Elsemary I. M. M, Abdel-Rehim A. A., Attia A. A. A. and Elnagar K. H., 2016, Optimization of stepped conical swirler with multiple jets for pre-mixed turbulent swirl flames, Applied Thermal Engineering, 102, 359-374.

Tret'yakov V. V., 2007, Calculation of fuel distribution in the combustion chamber front device equipped with a three-stage swirler, Russian Aeronautics, 50, 395-401.

Wang X., Lin Y., Zhang C. and Tian X., 2015, Effects of Swirl Cup's Secondary Swirler on Flow Field and Ignition Performance, Journal of Thermal Science, 24, 488-495.

Williams F. A., Combustion Theory, 1985, The Benjamin Cummings, 375-382.

Y1lmaz I.., Effect of Swirl Number on Combustion Charateristics in a Natural Gas Diffusion Flame, 2013, Journal of Energy Resources Technology, https://doi.org/10.1115/1.4024222 
Yihua X., Rui J., Humberto M. and Haijun S., 2019, Effect of Tangential Swirl Air Inlet Angle on the Combustion Efficiency of a Hybrid Powder-Solid Ramjet, Acta Astronautica, 159, 87-95.

Zhou L.X., 2018, Comparison of studies on flow and flame structures in different swirl combustors, Aerospace Science and Technology, 80, 29-37. 